UNIVERSIDADE DE SÃO PAULO

FACULDADE DE ECONOMIA, ADMINISTRAÇÃO E CONTABILIDADE DEPARTAMENTO DE ECONOMIA PROGRAMA DE PÓS-GRADUAÇÃO EM ECONOMIA

DESENVOLVIMENTO FINANCEIRO E ECONÔMICO-SOCIAL NOS MUNICÍPIOS BRASILEIROS

Leonardo Carvalho de Mello

Orientador: Prof. Dr. Carlos Eduardo Soares Gonçalves 
Prof. Dr. Marco Antonio Zago

Reitor da Universidade de São Paulo

Prof. Dr. Reinaldo Guerreiro

Diretor da Faculdade de Economia, Administração e Contabilidade

Prof. Dr. Joaquim José Martins Guilhoto

Chefe do Departamento de Economia

Prof. Dr. Márcio Issao Nakane

Coordenador do Programa de Pós-Graduação em Economia 


\title{
DESENVOLVIMENTO FINANCEIRO E ECONÔMICO-SOCIAL NOS
} MUNICÍPIOS BRASILEIROS

\author{
Dissertação apresentada ao Departamento \\ de Economia da Faculdade de Economia, \\ Administração e Contabilidade da \\ Universidade de São Paulo como requisito \\ para a obtenção do título de Mestre em \\ Ciências.
}

Orientador: Prof. Dr. Carlos Eduardo Soares Gonçalves

Versão Original

\section{SÃO PAULO}


FICHA CATALOGRÁFICA

Elaborada pela Seção de Processamento Técnico do SBD/FEA/USP

Mello, Leonardo Carvalho de

Desenvolvimento financeiro e econômico-social nos municípios brasileiros / Leonardo Carvalho de Mello. -- São Paulo, 2014.

$33 \mathrm{p}$.

Dissertação (Mestrado) - Universidade de São Paulo, 2014.

Orientador: Carlos Eduardo Soares Gonçalves.

1. Desenvolvimento econômico 2. Desenvolvimento financeiro 3. Distribuição de renda 4. Município - Brasil I. Universidade de São Paulo. Faculdade de Economia, Administração e Contabilidade. II. Título.

CDD - 338.9 


\section{AGRADECIMENTOS}

Antes de tudo, agradeço a Deus e à minha família, meu pai com sua curiosidade e conselhos, minha mãe com sua preocupação e seus conselhos, minha vó com suas preces e torcida e minha irmã, que sempre estiveram presentes em todos os momentos, dos mais alegres aos de maior dificuldade.

As pessoas mais próximas sabem quantos obstáculos tiveram que ser superados ao longo de minha vida para se chegar ao fim dessa etapa. Sabem do esforço empregado, dos momentos de grande tensão... Muitas pessoas me ajudaram e peço desculpas de antemão caso tenha me omitido em relação a alguém.

A oportunidade de ter sido aluno do mestrado do IPE-USP foi um grande sonho que se iniciou há cerca de cinco anos. Um sonho maior ainda do que a grande ousadia que foi concluir a graduação numa universidade pública. Esse sonho passou a se tornar realidade no final de 2011. Ele quase se transformou num pequeno pesadelo ao final do primeiro semestre de 2012 , mas provou ser uma experiência extremamente enriquecedora e importante, da qual sentirei muita saudade.

Tantas emoções foram compartilhadas por minha turma, pessoas fora de série, que influenciaram para que a trajetória dessa etapa fosse tão agradável como um todo e para que os momentos de dificuldade fossem amenizados. Em especial, agradeço àqueles com quem mais convivi: Bahia, Bruna, Dhan, Dimas, Fábio, Gabriel, Guilherme, Isabel, João, Júlia, Lucas, Luiz, Luísa, Maurício, Natália, Pedro e Perez. Tenho muito orgulho de ter podido compartilhar essa fase com todos e ter feito tantas amizades. Agradeço por todas as conversas que ajudaram para essa dissertação e destaco o rápido salto de patamar proporcionado pela ajuda do Maurício Matsumoto na etapa inicial da dissertação e aos comentários de Dimas, Fábio, Gabriel e Perez e aos conselhos de Isabel e Júlia.

Agradeço aos veteranos e a turma posterior pelas conversas, conselhos e ajudas. Em especial: Barufi, Sarah, Laura, Vivian, Rafael Proença, Dantas, Mariana e Neto.

Outra pessoa muito importante para a concretização desse projeto é Eduardo Yuki, que sempre frisou a importância dos estudos, principalmente do mestrado, e da consistência teórica para um economista e foi um grande incentivador e impulsionador desse projeto.

Agradeço ao meu orientador pelas conversas e sugestões que tanto contribuíram para superar as dificuldades envolvidas na pesquisa.

Além disso, agradeço ao Professor Gabriel Madeira e ao Depep do Banco Central do Brasil por terem disponibilizado os dados que viabilizaram essa dissertação e aos professores Mauro e Nakane pelos comentários e sugestões realizados na qualificação.

Por fim, agradeço a Capes pelo apoio financeiro. 
"Alea jacta est!"

(Tradução livre do autor: "A sorte está lançada!") Júlio César 


\section{RESUMO}

Há um intenso debate sobre o papel do crédito sobre o ciclo recente de expansão da economia brasileira. Esse trabalho pretende se inserir nesse debate ao testar resultados consagrados pela literatura empírica sobre as relações entre desenvolvimento financeiro e desenvolvimento econômico e social.

Além disso, discute-se a questão de má alocação de recursos no que diz respeito ao crédito concedido com base em recursos direcionados (em geral, por bancos públicos e subsidiado) em relação ao crédito alocado por recursos livres.

Os resultados sugerem maior eficiência alocativa do crédito livre em relação ao crédito direcionado.

Por outro lado, também indicam um instrumento de políticas públicas que tem contribuído para a redução da desigualdade e da pobreza. Ainda assim, é importante a ressalva da inexistência de uma estimativa precisa de quanto a sociedade está alocando para essas políticas nem se esses recursos poderiam obter resultados mais eficientes se alocados em outros tipos de políticas.

Esses resultados são sensíveis ao tamanho dos municípios medido pelo nível do PIB per capita, o que também sugere que uma dinâmica diferente do mercado de crédito e sua contribuição para o desenvolvimento. 


\begin{abstract}
There are a lot of discussions about the role of credit on the recent growth cycle of the Brazilian economy. This paper intends to be part of this debate by testing empirical results in the literature that relates financial development and social and economic development outcomes.

In addition, it discusses the issue of misallocation of resources specially comparing the earmarked credit concession (usually lent by public banks and with government subsidies) to free market credit.

The results indicate greater allocative efficiency of free credit in relation to earmarked credit.

On the other hand, they suggest that the earmarked credit is an instrument of public policy that has contributed to reduce poverty and inequality. Even though, it is important to caveat the lack of an accurate estimate of how much the society is allocating to this policy and what type of results would be achieved allocating this resources to other policies with the same goals.

These results are sensitive to the municipalities' size measured by GDP per capita level. It suggests a different dynamic to the credit market and its contribution to development.
\end{abstract}


SUMÁRIO

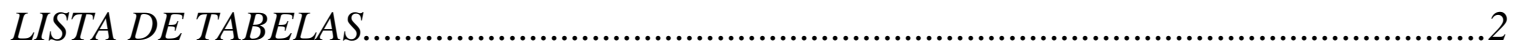

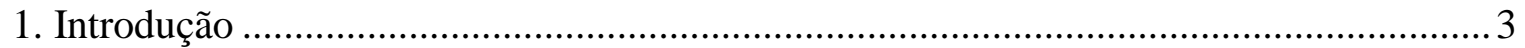

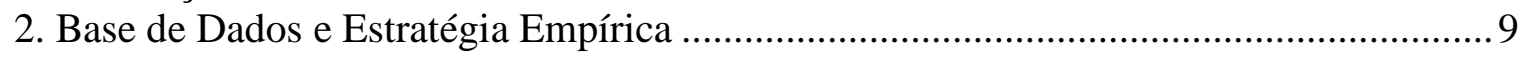

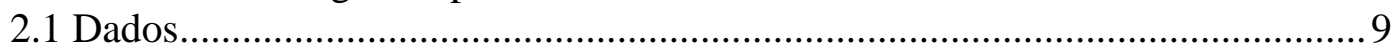

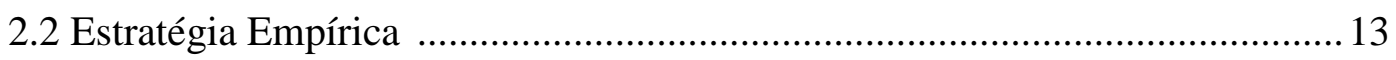

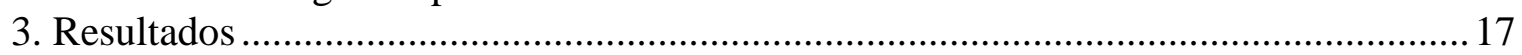

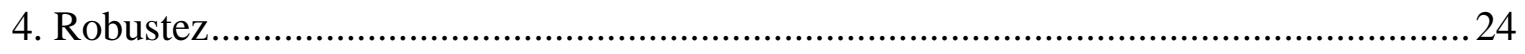

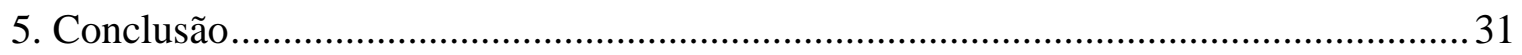

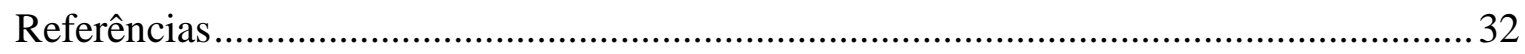




\section{LISTA DE TABELAS}

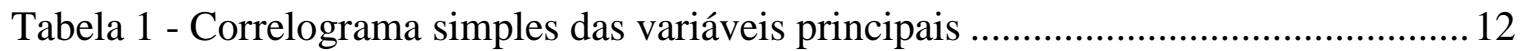

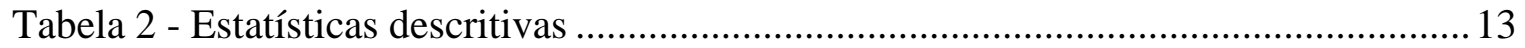

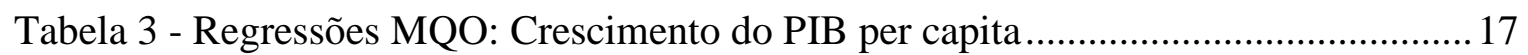

Tabela 4 - Regressões MQO: Variação do Gini .................................................................. 19

Tabela 5 - Regressões MQO: Variação da Pobreza Extrema ............................................20

Tabela 6 - Regressões MQO: Variação da Pobreza...........................................................20

Tabela 7 - Regressões Painel: Crescimento do PIB per capita .......................................22

Tabela 8a - Regressões MQO por percentil: PIB per capita x Crédito Total .....................24

Tabela 8b - Regressões MQO por percentil: PIB per capita x Crédito Origem .................25

Tabela 9a - Regressões Painel por percentil: PIB per capita x Crédito Total ....................26

Tabela 9b - Regressões Painel por percentil: PIB per capita x Crédito Origem ................. 26

Tabela 10a - Regressões MQO por percentil: Gini x Crédito Total .................................27

Tabela 10b - Regressões MQO por percentil: Gini x Crédito Origem ..............................2 27

Tabela 11a - Regressões MQO por percentil: Pobreza Extrema x Crédito Total..............28

Tabela 11b - Regressões MQO por percentil: Pobreza Extrema x Crédito Origem ...........29

Tabela 12a - Regressões MQO por percentil: Pobreza x Crédito Total .............................29

Tabela 12b - Regressões MQO por percentil: Pobreza x Crédito Origem ......................... 30 


\section{Introdução}

Muito tem sido discutido no Brasil sobre a importância da expansão do crédito para o crescimento apresentado recentemente. Na literatura internacional, o interesse sobre as relações entre desenvolvimento financeiro e crescimento econômico se iniciou no final da década de 1970 com o trabalho de Goldsmith (1969), seguido por McKinnon (1973) e Shaw (1973). Inicialmente, a abordagem questionava os motivos pelos quais desenvolvimento financeiro, ou repressão financeira poderiam influenciar no desenvolvimento econômico dos países. Em resumo, Goldsmith encontra uma correlação positiva entre crescimento econômico e desenvolvimento financeiro. Isso será estudado no presente trabalho para o Brasil.

Nos anos 1990, o interesse pelo tema retomou força e a construção de novas bases de dados e modelos teóricos permitiram a evolução de trabalhos como King \& Levine (1993), que é um marco dessa literatura ao mensurar o impacto causal de desenvolvimento financeiro para o crescimento. A estratégia consiste em utilizar as variáveis de desenvolvimento financeiro em momentos anteriores aos das variáveis dependentes analisadas, "os indicadores de crescimento": crescimento do PIB per capita, taxa de acumulação do capital e melhora da eficiência econômica. Os resultados obtidos para 80 países entre 1960 e 1989 sugerem, além da correlação positiva contemporânea entre o desenvolvimento financeiro e os indicadores de crescimento, a existência de uma forte relação positiva entre os indicadores de crescimento futuros (para períodos entre 10 e 30 anos) e o desenvolvimento financeiro inicial. O presente trabalho não poderá ser estendido para um período tão longo de tempo por limitação dos dados obtidos, mas executará uma abordagem semelhante.

Um passo adiante na tentativa de isolar causalidade de desenvolvimento financeiro para crescimento é de La Porta et al (1998). Esse trabalho busca as origens dos sistemas legais dos diferentes países e argumenta sobre a existência de exogeneidade entre origem legal e concessão de crédito por precedência temporal, pois os sistemas legais são formados em períodos muito anteriores aos analisados e repassados para muitos países via colonização. $\mathrm{O}$ único canal pelo qual os autores argumentam que a origem legal impactaria no crescimento dos países seria pelo melhor ambiente para credores. 
Assim, haveria maior concessão de empréstimos em países com origem legal inglesa, a common law, e isso geraria um crescimento mais elevado. Contudo, esse tipo de abordagem não pôde ser desenvolvida no presente trabalho, pelo fato dos municípios brasileiros estarem no mesmo ambiente jurídico de jure. Há uma discussão em Naritomi, Soares \& Assunção (2007) sobre a existência de diferentes ambientes de fato no Brasil, mas o escopo do presente trabalho sofreria grande perda da amostra para trabalhar apenas nas regiões propostas naquele estudo.

A justificativa teórica para os trabalhos apresentados empíricos apresentados até aqui se desenvolveu a partir da aplicação de modelos de equilíbrio geral como em Greenwood \& Jovanovic (1990) e Bencivenga \& Smith (1991), os quais buscam um tratamento mais formal sobre quais seriam os canais micro fundamentados pelos quais o desenvolvimento financeiro é um fator importante para o crescimento. Em resumo, como firmas estão sujeitas a choques idiossincráticos, as instituições financeiras ajudam a eliminar o risco associado a choques de produtividade via portfólios diversificados. Além disso, indivíduos estão sujeitos a choques de liquidez e podem requerer capital investido nas firmas antes da maturação do investimento (num estado de autarquia, sem instituições financeiras), assim instituições financeiras provêm liquidez às firmas e aumentam o total de recursos investidos na economia. Por fim, instituições financeiras possuem menor custo de avaliar risco moral das firmas tomadoras, já que alguns tomadores têm projetos com pouca chance de sucesso ex ante a concessão de crédito.

Recentemente, alguns estudos têm analisado dados locais dentro de países específicos e, nesse sentido, são semelhantes ao presente trabalho. Em geral, são situações que se aproximam de estudos quase-experimentais. Dentre esses estudos, destacam-se: Jayaratne \& Strahan (1996), Guiso, Sapienza \& Zingales (2004) e Burguess \& Pande (2005).

Em Jayaratne \& Strahan (1996), há descrição sobre a evolução da legislação dos EUA para abertura de filiais de bancos locais que seria muito restrita na década de 1970 e foi gradualmente desregulamentada por vários estados ao longo das décadas seguintes. Essa desregulamentação não foi uniforme, e segundo os autores, não parece ter sido causada com o intuito de gerar crescimento na maioria dos casos. Entretanto, os próprios autores comentam que esse foi o principal motivo em alguns casos e isso invalidaria a hipótese de 
identificação utilizada. A metodologia adotada utiliza dados em painel e utilizava variáveis dummy para os estados onde ocorria desregulamentação. O impacto da desregulamentação para o crescimento é positivo, significativo e robusto a várias especificações. Entretanto, não é obtido impacto significativo da desregulamentação para a expansão quantitativa do crédito. Os autores argumentam em linha com Greenwood \& Jovanovic (1990). Ou seja, maior desenvolvimento financeiro causado pela desregulamentação elevaria a eficiência do investimento. Isto é, aumento da produtividade marginal do capital pela melhor capacidade de monitoramento possibilitada por instituições maiores.

Já o trabalho de Guiso, Sapienza \& Zingales (2004) analisa o desenvolvimento financeiro regional na Itália. A motivação para esse tipo de análise dentro de um país, que também será executada no presente trabalho, é feita pelo seguinte argumento: ao encontrar um resultado positivo (de desenvolvimento financeiro para crescimento) nos dados dentro do país, isso pode ser extrapolado para o país como um todo e reforça resultados positivos em análises cross country. A estratégia de identificação é minimizar o possível canal direto que capital social, um dos instrumentos utilizados, poderia ter para o crescimento que não fosse através de expansão do crédito (medida de desenvolvimento financeiro). Entretanto, é difícil ser suficientemente convincente de que o único canal pelo qual instituições afetam crescimento é através do crédito. Além do capital social das firmas, a eficiência judicial também é utilizada como instrumento e pouco se argumenta em favor desse instrumento, apesar da possibilidade de outros canais de impacto para o crescimento, além do crédito. Em resumo, os resultados encontrados sugerem um forte aumento na probabilidade, cerca de 33\%, de um indivíduo ter uma empresa própria, caso se mova da região menos desenvolvida financeiramente na Itália para a mais desenvolvida, ou seja, há melhores condições para o crescimento econômico nas regiões mais desenvolvidas financeiramente.

Num contexto de experimento social, Burguess \& Pande (2005) avalia o impacto de um grande programa de expansão de agências na Índia liderado por bancos estatais. Entre 1977 e 1990, o Banco Central da Índia passou a exigir a abertura de quatro agências em zonas rurais sem agências para a concessão de licença para abrir uma agência onde o setor bancário já estivesse presente (Programa 1:4). Além disso, entre 1969 e 1990, taxas de juros rurais para tomadores de empréstimos eram reduzidas e para poupadores 
aumentadas, ambas por subsídios do governo. Os resultados obtidos indicam que o programa de expansão de agências aumentou poupança e concessão de crédito na zona rural indiana. Além disso, verifica-se que, entre 1970 e 1978, a pobreza caiu mais em áreas financeiramente mais desenvolvidas. O inverso ocorre entre 1983 e 1990. Ao encontrar efeito significativo do desenvolvimento financeiro para a redução da pobreza esse trabalho tem relação com alguns resultados encontrados no presente trabalho, em especial, considerando alguma similaridade entre o crédito direcionado indiano e o brasileiro.

Isso remete a outra questão do debate corrente de grande importância: a questão da má alocação de recursos, tratada em trabalhos como Hsieh \& Klenow (2009) e Restuccia e Rogerson (2008). Para deixar mais evidente a ideia de má alocação de recursos, vale retomar um dos modelos apresentados em Hsieh \& Klenow (2009): uma economia simples com duas firmas que possuam funções de produção idênticas, sendo que uma delas tem melhores conexões políticas e com isso maior acesso ao crédito subsidiado e/ou direcionado. Dessa forma, o produto marginal do capital dessa firma tende a ser mais baixo do que o da outra firma. Assim, o produto agregado da economia poderia ser mais alto se houvesse equalização de taxas de juros e consequentemente entre os produtos marginais do capital.

Muito se discute no Brasil sobre a eficiência da alocação de recursos de origem direcionada, majoritariamente ofertados por bancos públicos e com taxas de juros subsidiadas. O presente estudo contribui no sentido de gerar elementos para checar a eficiência alocativa dos recursos de origem direcionada em comparação aos recursos de origem livre. Ao mesmo tempo, ao levar em conta outros indicadores de desenvolvimento social, amplia-se o escopo da análise para o campo da justiça, isto é, se esses recursos teriam algum efeito na variação da equidade distributiva dos recursos.

O presente trabalho dialoga com a literatura por meio da análise de dados de desenvolvimento financeiro dos municípios brasileiros. Utilizam-se dados agregados não públicos do Sistema de Informações de Crédito (SCR) obtidos junto ao Banco Central do Brasil. Dessa base, que contém informações detalhadas sobre todos os contratos de crédito formal estabelecidos em território nacional com valores acima de cinco mil reais e que, até hoje, foi pouco explorada, foram disponibilizados dados agregados por 
municípios entre 2003 e 2008 para o crédito livre e o direcionado. Observa-se que a elevada participação do crédito direcionado e subsidiado é uma peculiaridade brasileira, o que torna ainda mais instigante uma análise mais completa sobre o desenvolvimento financeiro brasileiro e sua relação com o desenvolvimento socioeconômico.

A estratégia empírica adotada é seguir, até onde os dados permitem, Levine et al (2000) e Barro \& Sala-i-Martin (1992). Isto é, utilizar variáveis dependentes que mensuram desenvolvimento socioeconômico, como: crescimento do PIB per capita, variação da desigualdade medida pela variação do índice de Gini e variação da pobreza. A partir dessas variáveis, checa-se a correlação com variáveis explicativas como: crédito total per capita, ou em especificações que consideram a diferenciação entre crédito livre e direcionado controlando para convergência não condicional, capital humano e transferências da União para municípios.

A análise também considera um painel de efeito fixo com dois períodos, 2003 a 2005 e 2006 a 2008, para o crescimento do PIB per capita. A limitação de disponibilidade de dados não permite uma estratégia de análise equivalente para as variáveis dependentes desigualdade e pobreza.

Em resumo, encontra-se uma relação positiva estatisticamente pouco robusta entre crédito total per capita e crescimento como se pensaria a priori. Entretanto, a correlação controlada entre crédito livre per capita e crescimento do PIB per capita é positiva e, em geral, superior estatisticamente à correlação controlada entre crédito direcionado per capita e crescimento do PIB per capita, o que validaria a ideia de ineficiência alocativa do crédito direcionado.

Por outro lado, observa-se uma correlação controlada negativa e robusta entre crédito direcionado per capita e variação da desigualdade e da pobreza. Essa correlação é, em valor, mais negativa do que a correlação do crédito livre per capita com as mesmas variáveis, sendo que os valores são estatisticamente significativos na grande maioria das especificações estimadas. Ou seja, apesar da menor eficiência em favorecer o crescimento, o crédito direcionado tem contribuído para redução da desigualdade e da pobreza, e também, para uma distribuição mais equitativa dos recursos. 
Entretanto, valem algumas ressalvas. Em primeiro lugar, grande parte desses recursos de origem direcionada contêm subsídios governamentais, como, por exemplo, aqueles concedidos pelo BNDES, que constituem cerca de $58 \%$ do crédito direcionado. Esse subsídio não é contabilizado com acurácia no orçamento da União. Além disso, não é possível inferir como seria o funcionamento do mercado de crédito sem medidas de direcionamento de recursos, pois muitos economistas têm argumentado que parte do crédito direcionado (novamente com destaque para as concessões do BNDES) tem ocupado o espaço que poderia ser suprido pelo crédito livre.

O trabalho segue com a apresentação dos dados e das formas funcionais das estimações na próxima seção. Passa-se à apresentação e discussão dos resultados das estimações na seção 3. A seção 4 aprofunda a discussão dos resultados da seção anterior com novas estimações. Por fim, as conclusões são apresentadas na seção 5. 


\section{Base de Dados e Estratégia Empírica}

Nessa seção, é apresentada uma descrição sobre a base de dados utilizada neste estudo para investigar a relação entre desenvolvimento financeiro e desenvolvimento socioeconômico no caso brasileiro. Ainda, aprofunda-se aqui a discussão sobre a distinção entre crédito livre e direcionado, a principal novidade deste trabalho em relação aos existentes. Por fim, justifica-se a forma funcional das equações a serem estimadas.

\subsection{Dados}

A principal variável explicativa explorada é o desenvolvimento financeiro. Considerandose as muitas possibilidades de variáveis exploradas pela literatura para medir desenvolvimento financeiro, o crédito foi a variável utilizada para cumprir esse objetivo.

A escolha do crédito é padrão em trabalhos semelhantes para países (Levine, 1992) e para estados brasileiros (Zara, 2006) e também se justifica pelos dados de crédito obtidos, que são provenientes de uma parceria acadêmica entre o Banco Central do Brasil (Bacen) e o Professor Gabriel de Abreu Madeira. São dados não públicos de concessão de crédito, que foram fornecidos agregadamente para cada munícipio para o fim de cada ano entre 2003 e 2008. Duas vantagens que justificam a utilização dessa base em detrimento de outra base de dados de crédito comumente utilizada em estudos brasileiros do tema, o Estban, é a possibilidade de distinguir os créditos livre e direcionado e a agregação dos saldos de crédito pelo município do tomador ao invés do município da instituição financeira emprestadora.

No Estban, muito utilizado em trabalhos anteriores por ser uma base de acesso público, o valor do crédito é contabilizado pelo local onde está situada a instituição financeira que firmou o contrato de crédito. Com isso, a questão de origem e aplicação do crédito é mais problemática. Por exemplo, uma grande instituição financeira registrará grande quantidade de crédito concedido num município, se aquele município for sua sede. Entretanto, a probabilidade desses recursos serem empregados nesse mesmo município é muito menor do que se fosse considerada a sede do tomador (caso ele seja Pessoa 
Jurídica) ou a residência do mesmo (caso ele seja Pessoa Física), que é a forma como os dados são obtidos no SCR.

Segundo o Bacen ${ }^{1}$, o SCR é constituído por informações prestadas pelas instituições financeiras sobre suas operações de crédito. Inicialmente, as instituições eram obrigadas a informar operações de crédito com valor igual ou superior a cinquenta mil reais. Esse valor foi gradualmente reduzido ao longo do tempo até cinco mil reais e, em 2012, foi reduzido a mil reais. Além disso, a coleta e compartilhamento dos dados e sua relação com o sigilo bancário do cliente da instituição financeira são amparados pela Lei Complementar 105/01 e pela Resolução 3.658 de 17/12/2008. Por fim, os arquivos recebidos pelo Bacen passam por um processo de verificação, em que se busca testar a consistência das informações prestadas.

Os dados obtidos se enquadram no período no qual o limite mínimo para o envio de dados pelas instituições financeiras era de cinco mil reais. Trata-se do volume de crédito, de origem livre e direcionada, concedido em dezembro dos anos de 2003 a 2008.

Uma dificuldade encontrada nos dados obtidos é a não identificação individual dos municípios homônimos. Mais especificamente, munícipios com o mesmo nome foram agregados como um único indivíduo na amostra disponibilizada. Assume-se que a característica de ser homônimo é aleatória, logo esses municípios foram descartados da análise a ser realizada. Esses municípios contabilizam pouco mais de $10 \%$ dos indivíduos da amostra (entre 10,4\% e 11,9\% dos municípios), cujo universo era de 5565 municípios em 2008. Municípios que sofreram trocas de nome e separação, também foram identificados. Em alguns poucos casos, foram excluídos (cerca de 0,1\% do total), em outros, foi possível mantê-los na base de dados.

Seguindo a literatura, uma das variáveis dependentes analisadas é o crescimento do PIB per capita. O PIB per capita é obtido pela divisão dos dados de PIB e estimativa de população municipal coletados e/ou estimados e disponibilizados publicamente pelo IBGE entre os anos de 2003 a 2008.

\footnotetext{
${ }^{1}$ Informações detalhadas sobre o SCR podem ser obtidos em: http://www.bcb.gov.br/?SCROQUE
} 
Os dados do PIB municipal e de crédito são nominais. Eles foram deflacionados pelo deflator implícito do PIB nacional e estão denominados em milhares de Reais a valores de 2003.

Outras variáveis dependentes são: índice de Gini e medidas de pobreza. Ambos são calculados em nível municipal com base nos Censos de 2000 e 2010 pelo Instituto de Pesquisa Econômica Aplicada (IPEA).

A primeira medida de pobreza, chamada, de agora em diante, de pobreza extrema, contabiliza, em 2000 e 2010, a proporção da população do município com renda inferior a um quarto de salário mínimo em valores reais de $2010^{2}$.

A segunda medida de pobreza, mais ampla e chamada, de agora em diante, de pobreza, contabiliza, em 2000 e 2010, a proporção da população do município com renda inferior a meio salário mínimo em valores reais de 2010.

Uma das variáveis de controle a serem utilizadas e, cujo uso será discutido logo a seguir, é o capital humano mensurado pela escolaridade média da população acima de 25 anos, para cada município, disponibilizada pelo IBGE no Censo de 2000 como uma variável de controle.

Além disso, a variável transferência da União real per capita para municípios também foi utilizada como controle, pois se espera que afete o crescimento municipal (principalmente para municípios pequenos) e potencialmente está correlacionada com o crédito direcionado. Essa variável é obtida junto ao Finbra e foi deflacionada para valores reais de 2003 e medida em milhares de reais per capita.

Para as estimações que envolvem variação de pobreza é necessário controlar a presença do programa bolsa-família, que não é capturado diretamente nas transferências da União, apresentadas no parágrafo anterior. Para isso, foram utilizadas várias medidas de bolsafamília, como quantidade de beneficiários, valor do benefício no período inicial, valor total recebido pelo município no período 2004 a 2010. A medida apresentada logo a

\footnotetext{
${ }^{2}$ O valor do salário mínimo considerado é de 510 reais em 2010
} 
seguir e nas tabelas de estimação é o valor total proveniente de bolsa-família entre 2004 e 2008 em valores reais de 2003, deflacionado pelo método descrito para as demais variáveis nominais. Os resultados apresentados na próxima seção não apresentaram sensibilidade às diferentes formas de cômputo do programa.

A Tabela 1 traz as correlações simples entre as principais variáveis utilizadas nesse trabalho.

Tabela 1 - Correlograma simples das variáveis principais

\begin{tabular}{|c|c|c|c|c|c|c|c|c|c|c|c|}
\hline & Cresc PIB pc & c Var. Pobreza Ext & Var. Pobreza & Var. Gini & i Crédito Total & I Crédito Livre & Crédito Direcio & PIB pc 2003 & 3 Escolaridade & Transferência & Bolsa-Família \\
\hline Cresc PIB pc & 1.00 & & & & & & & & & & \\
\hline Var. Pobreza Ext & 0.03 & 1.00 & & & & & & & & & \\
\hline Var. Pobreza & 0.10 & 0.74 & 1.00 & & & & & & & & \\
\hline Var. Gini & 0.04 & 0.36 & 0.29 & 1.00 & & & & & & & \\
\hline Crédito Total & -0.09 & -0.13 & -0.37 & -0.08 & 1.00 & & & & & & \\
\hline Crédito Livre & -0.05 & -0.07 & -0.30 & -0.05 & 0.85 & 1.00 & & & & & \\
\hline Crédito Direcio & -0.10 & -0.15 & -0.35 & -0.09 & 0.91 & 0.56 & 1.00 & & & & \\
\hline PIB pc 2003 & -0.14 & -0.14 & -0.37 & -0.07 & 0.52 & 0.47 & 0.46 & 1.00 & & & \\
\hline Escolaridade & -0.11 & -0.28 & -0.59 & -0.11 & 0.45 & 0.46 & 0.34 & 0.47 & 1.00 & & \\
\hline Transferência & -0.02 & -0.20 & -0.22 & -0.02 & -0.04 & -0.11 & 0.02 & 0.05 & -0.08 & 1.00 & \\
\hline Bolsa-Família & 0.11 & 0.33 & 0.68 & 0.13 & -0.43 & -0.40 & -0.36 & -0.48 & -0.81 & -0.04 & 1.00 \\
\hline
\end{tabular}

Na Tabela 1, há uma correlação negativa simples entre crescimento do PIB per capita e crédito (total, direcionado e livre). Além disso, o crédito livre é positivamente correlacionado $(0,56)$ com o crédito direcionado.

Já a Tabela 2 traz as principais estatísticas descritivas das variáveis utilizadas nesse trabalho. 
Tabela 2 - Estatísticas descritivas

\begin{tabular}{lccccc}
\hline & Obs. & Média & Desvio-Padrão & Mín. & Máx. \\
\hline Cresc PIB pc & 5028 & 0.20 & 0.47 & -0.85 & 15.69 \\
Var. Pobreza Extrema & 5507 & -0.46 & 0.21 & -1.00 & 2.70 \\
Var. Pobreza & 5507 & -0.33 & 0.17 & -0.94 & 0.48 \\
Var. Gini & 5507 & -0.09 & 0.11 & -0.50 & 0.46 \\
Crédito Livre & 4989 & 0.469 & 0.908 & 0.003 & 20 \\
Crédito Direcionado & 4924 & 0.640 & 3.424 & 0.001 & 226 \\
Crédito Total & 4902 & 1.119 & 3.715 & 0.006 & 226 \\
PIB pc 2003 & 5028 & 5.764 & 6.427 & 0.921 & 151 \\
Escolaridade & 4979 & 4.0 & 1.3 & 0.8 & 9.7 \\
Transferências União & 5401 & 0.338 & 0.213 & 0.028 & 3.495 \\
Bolsa-Família & 5001 & 3.843 & 2.349 & 0.103 & 14.039 \\
\hline
\end{tabular}

\subsection{Estratégia Empírica}

Os estudos sobre convergência de produto, realizados por Barro (1991) e Barro e Sala-iMartin (1992) são o ponto de partida das estimações da literatura com a qual esse trabalho dialoga, como Levine (1992), Yeyati, Micco e Panizza (2004), Zara (2006), no que diz respeito à forma funcional e aos controles das regressões a serem estimadas.

Barro \& Sala-i-Martin (1992) trabalham com dados de estados do EUA. Verifica-se, com elevada robustez, a convergência de crescimento do produto entre os estados. Isto é, considerando-se como variável dependente o crescimento do PIB per capita local (medido por fontes distintas em diferentes períodos de tempo) e considerando apenas o nível de PIB per capita inicial como variável explicativa, estimadores consistentemente negativos são obtidos. Ou seja, estados com maior nível de produto per capita, no período inicial, tem menor crescimento do que os estados com produto menor. Ou seja, é encontrada uma convergência de renda entre eles.

Entretanto, quando se estende o mesmo método para estudar diferenças entre países, essa convergência não é observada. Justifica-se a necessidade de outros controles, pois a imobilidade de capitais, diferença institucional e principalmente a disponibilidade do capital humano são muito distintas quando se passa de um estudo entre regiões de um mesmo país para um estudo entre países. Em outras palavras, os países possuem 
diferentes estados estacionários. Logo, ao inserir o controle de capital humano na regressão anterior, medido por média de anos de estudo da população adulta, encontra-se forte efeito de convergência entre países, por isso, essa característica foi nomeada convergência condicional.

Adicionalmente, outro problema recorrente na literatura é a busca por instrumentos que permitam a obtenção de efeito causal entre desenvolvimento financeiro $\mathrm{e}$ desenvolvimento econômico. A estratégia adotada no presente trabalho não pretende fazer uma análise de inferência causal e há consciência dos problemas potenciais de estimação viesada dos coeficientes. Para tentar solucionar parcialmente essas questões, utiliza-se um painel de efeitos fixos sempre que os dados permitam. Além disso, é buscada parcimônia na presença de variáveis de controle que poderiam viesar ainda mais os coeficientes de interesse na análise cross section por endogeneidade com a variável dependente por simultaneidade.

Dessa forma, explicita-se a estratégia adotada de evitar o uso de demasiadas variáveis de controle para evitar a endogeneidade potencial e as consequências que isso pode trazer para a estimação em cross section.

Portanto, a primeira equação de interesse é a que relaciona as variáveis dependentes de interesse (medidas de desenvolvimento econômico e social), o crédito total os demais controles. Trata-se da equação 1:

$$
\begin{gathered}
\text { (1) } y_{i}=\beta_{0}+\beta_{1} \text { CredTotP }_{i}+\beta_{2} \text { pibP }_{i}+\beta_{3} \text { escolaridade }_{i}+ \\
\beta_{4} \text { TransUniãoP }_{i}+u_{i}
\end{gathered}
$$

Sendo que:

$i=$ municípios brasileiros.

$y_{i}=$ crescimento do PIB per capita entre 2003 e 2008 ou redução percentual da pobreza/Gini entre 2000 e 2010.

CredTotPC $_{i}=$ nível de crédito médio real per capita entre 2003 e 2008.

$p i b P C_{i}=$ nível do PIB per capita real em 2003.

escolaridade $_{i}=$ média de anos de estudo da população do município i em 2000. 
TransUniãoP $C_{i}=$ transferências da União para o município $i$ em 2003.

Outra estimação, que pretende explorar as possíveis distinções entre crédito livre e direcionado é dada pela equação 2:

(2) $y_{i}=\beta_{0}+\beta_{1}$ CredLivPC $_{i}+\beta_{2}$ CredDirPC $_{i}+\beta_{3}$ pibPC $_{i}+\beta_{4}$ escolaridade $_{i}+$

$$
\beta_{5} \text { TransUniãoPC } i+u_{i}
$$

Sendo que adicionalmente à equação 1:

CredLivPC $_{i}=$ nível de crédito, com origem em recursos livres, médio real per capita entre 2003 e 2008.

CredDirPC $_{i}=$ nível de crédito, com origem em recursos direcionados, médio real per capita entre 2003 e 2008.

Aplica-se um painel de efeitos fixos para controlar características não observadas e constantes no tempo. Essa estimação é o objetivo da equação 3:

$$
\text { (3) } y_{i t}=\alpha_{i}+\beta_{1} \text { CredTotPC }_{i t}+\beta_{2} p i b P C_{i t}+\beta_{3} d u m m y_{t}+u_{i t}
$$

Sendo que:

$\mathrm{t}=1$, para o período 2003 a 2005 .

$\mathrm{t}=2$, para o período 2006 a 2008 .

$p i b P C_{i t}=$ nível do PIB per capita real em 2003, quando $\mathrm{t}=1$, e em 2006, quanto $\mathrm{t}=2$.

dummy $_{t}=$ dummy de tempo. É igual a 1 , quando $\mathrm{t}=1$, e 0 , quanto $\mathrm{t}=2$.

A escolha de duas janelas de tempo de três anos é justificada pela tentativa de evitar o impacto dos ciclos na análise das correlações e pela restrição da dimensão temporal da amostra do painel ${ }^{3}$.

\footnotetext{
${ }^{3}$ Idealmente, haveria janelas de 5 anos. Esse é o período de duração de um ciclo econômico registrado pela literatura, mas há indisponibilidade de dados para tanto até o momento.
} 
A inclusão de uma dummy de tempo tem por objetivo controlar possíveis choques agregados entre o primeiro e o segundo períodos.

Analogamente ao procedimento adotado em cross section, há interesse na distinção entre crédito livre e direcionado na abordagem do painel de efeito fixo. Essa estimação é realizada pela equação 4 :

(4) $y_{i t}=\alpha_{i}+\beta_{1} \operatorname{CredLivPC}_{i t}+\beta_{2} \operatorname{CredDirPC}_{i t}+\beta_{3} p i b P C_{i t}+\beta_{4} d u m m y_{t}+u_{i t}$ 


\section{Resultados}

Nessa seção, apresentam-se os resultados das estimações das regressões discutidas na seção anterior. Um dos objetivos é checar se as correlações encontradas estão de acordo com a teoria e com trabalhos empíricos anteriores. A principal inovação será observar se a origem dos recursos do crédito, livre ou direcionada, apresenta correlações diferentes com as variáveis de desenvolvimento econômico e social. Isso poderia sugerir uma forma distinta de atuação do crédito brasileiro de acordo com a fonte dos recursos.

As Tabelas 3 a 6 apresentam os resultados das estimações anteriormente apresentadas para as seguintes variáveis dependentes: crescimento do PIB per capita, variação da desigualdade e variação de cada uma das duas medidas de proporção de pobres anteriormente discutidas.

As colunas 1 a 3 apresentam os resultados das estimações de diferentes especificações (variação da presença de controles) para a equação (1) e as colunas de 4 a 6 os resultados da equação (2) para as diferentes variáveis dependentes. Em seguida, cada tabela será discutida separadamente.

Tabela 3 - Regressões MQO: Crescimento do PIB per capita

Dependent Variable Cresc PIB pc

\begin{tabular}{|c|c|c|c|c|c|c|}
\hline \multirow[b]{3}{*}{ Crédito Total } & 1 & 2 & 3 & 4 & 5 & 6 \\
\hline & \multicolumn{3}{|c|}{ Crédito Total } & \multicolumn{3}{|c|}{ Crédito Livre e Direcionado } \\
\hline & $0.0034^{*}$ & -0.0001 & 0.0002 & & & \\
\hline & [1.7990] & {$[-0.0176]$} & {$[0.0546]$} & & & \\
\hline \multirow[t]{2}{*}{ PIB pc 2003} & $-0.0106 * * *$ & $-0.0078 * * *$ & $-0.0085^{* * *}$ & $-0.0111 * * *$ & $-0.0078 * * *$ & $-0.0086 * * *$ \\
\hline & {$[-9.8951]$} & {$[-6.0050]$} & {$[-6.2676]$} & {$[-9.5407]$} & {$[-6.0378]$} & {$[-6.3283]$} \\
\hline \multirow[t]{2}{*}{ Escolaridade } & & $-0.0236 * * *$ & $-0.0216 * * *$ & & $-0.0291 * * *$ & $-0.0265 * * *$ \\
\hline & & {$[-3.8291]$} & {$[-3.4100]$} & & {$[-4.6630]$} & {$[-4.1395]$} \\
\hline \multirow[t]{2}{*}{ Transferências União } & & & -0.035 & & & -0.0129 \\
\hline & & & {$[-1.0359]$} & & & {$[-0.3797]$} \\
\hline \multirow[t]{2}{*}{ Crédito Direcionado } & & & & 0.0026 & $-0.0284 * * *$ & $-0.0268 * * *$ \\
\hline & & & & [1.2958] & {$[-4.0329]$} & {$[-3.7426]$} \\
\hline \multirow[t]{2}{*}{ Crédito Livre } & & & & 0.0125 & $0.0434 * * *$ & $0.0417 * * *$ \\
\hline & & & & [1.5146] & {$[4.5536]$} & [4.3017] \\
\hline \multirow[t]{2}{*}{ Constant } & $0.2542^{* * *}$ & $0.3381^{* * *}$ & $0.3435 * * *$ & $0.2534 * * *$ & $0.3566 * * *$ & $0.3528 * * *$ \\
\hline & [28.2603] & {$[14.4042]$} & {$[12.5006]$} & {$[28.0866]$} & {$[15.0566]$} & {$[12.8356]$} \\
\hline R-squared & 0.019 & 0.021 & 0.021 & 0.019 & 0.026 & 0.026 \\
\hline Liv=Dir & & & & 0.2552 & 0.0000 & 0.0000 \\
\hline $\mathrm{N}$ & 4902 & 4853 & 4719 & 4902 & 4853 & 4719 \\
\hline
\end{tabular}


Uma primeira característica muito marcante das estimações obtidas na Tabela 3 é a confirmação do expressivo efeito de convergência discutido na seção anterior. Isto é, em geral, os municípios com nível de PIB per capita mais baixo em 2003, foram os que apresentaram maior crescimento econômico no período.

Outro resultado importante é a correlação controlada positiva entre crédito livre e o crescimento do PIB per capita no período, resultado que aponta para a mesma direção dos estudos apresentados até aqui. Entretanto, um resultado que chama atenção é a ausência de correlação positiva e estatisticamente significativa entre crédito total e crescimento. As regressões 4 a 6 sugerem uma possível explicação para esse resultado, pois é encontrada uma correlação controlada negativa entre crédito direcionado e crescimento, ou seja, isso seria um indício de maior eficiência do crédito cuja origem é de recursos livres. Entretanto, apesar dessa possibilidade, esse coeficiente negativo não é confirmado nas estimações de painel de Efeitos Fixos, que como explicado anteriormente são estimativas mais robustas por considerarem mais fatores sob controle. Isso voltará a ser mais discutido mais adiante.

Um exercício simples permite ressaltar a importância econômica dos resultados obtidos: considere um aumento de um desvio-padrão do crédito livre, que de acordo com a Tabela 2, apresentada na seção anterior é igual a 0,9. Multiplicando esse valor pelo coeficiente obtido na regressão com maior número de controles para o crédito livre $(0,0417)$, seria obtido 0,0375. Considerando que o crescimento médio do período foi de 0,2 , resulta em cerca de $18 \%$ do crescimento per capita deste período correlacionado com o nível de crédito livre per capita médio do período. 
Tabela 4 - Regressões MQO: Variação do Gini

\begin{tabular}{|c|c|c|c|c|c|c|}
\hline \multirow[t]{2}{*}{ Dependent Variable } & \multicolumn{6}{|l|}{ Var. Gini } \\
\hline & 1 & 2 & 3 & 4 & 5 & 6 \\
\hline & \multicolumn{3}{|c|}{ Crédito Total } & \multicolumn{3}{|c|}{ Crédito Livre e Direcionado } \\
\hline \multirow[t]{2}{*}{ Crédito Total } & $-0.0037^{* * *}$ & $-0.0020^{*}$ & $-0.0022^{* *}$ & & & \\
\hline & {$[-3.5923]$} & {$[-1.8784]$} & {$[-2.0740]$} & & & \\
\hline \multirow[t]{2}{*}{ PIB pc 2003} & $-0.0009 * * *$ & -0.0003 & -0.0002 & $-0.0010^{* * *}$ & -0.0003 & -0.0002 \\
\hline & {$[-3.0503]$} & {$[-1.0566]$} & {$[-0.5544]$} & {$[-3.1955]$} & {$[-1.0699]$} & {$[-0.5867]$} \\
\hline \multirow[t]{2}{*}{ Escolaridade } & & $-0.0089 * * *$ & $-0.0085^{* * *}$ & & $-0.0099 * * *$ & $-0.0093 * * *$ \\
\hline & & {$[-6.0255]$} & {$[-5.6173]$} & & {$[-6.5657]$} & {$[-6.0773]$} \\
\hline \multirow[t]{2}{*}{ Transferências União } & & & $-0.0179 * *$ & & & $-0.0143^{*}$ \\
\hline & & & {$[-2.2182]$} & & & {$[-1.7542]$} \\
\hline \multirow[t]{2}{*}{ Crédito Direcionado } & & & & $-0.0071^{* * *}$ & $-0.0068 * * *$ & $-0.0066^{* * *}$ \\
\hline & & & & {$[-4.1778]$} & {$[-4.0098]$} & {$[-3.8796]$} \\
\hline \multirow[t]{2}{*}{ Crédito Livre } & & & & 0.0013 & $0.0054^{* *}$ & $0.0046^{* *}$ \\
\hline & & & & [0.5899] & {$[2.3581]$} & [1.9907] \\
\hline \multirow[t]{2}{*}{ Constant } & $-0.0787^{* * *}$ & $-0.0473 * * *$ & $-0.0449 * * *$ & $-0.0787^{* * *}$ & $-0.0442^{* * *}$ & $-0.0434^{* * *}$ \\
\hline & {$[-35.7858]$} & {$[-8.3869]$} & {$[-6.8476]$} & {$[-35.8397]$} & {$[-7.7451]$} & {$[-6.6068]$} \\
\hline R-squared & 0.009 & 0.016 & 0.015 & 0.01 & 0.019 & 0.017 \\
\hline Liv=Dir & & & & 0.0115 & 0.0003 & 0.0010 \\
\hline $\mathrm{N}$ & 4853 & 4853 & 4719 & 4853 & 4853 & 4719 \\
\hline
\end{tabular}

Em seguida, a Tabela 4 apresenta uma correlação negativa entre crédito total e variação da desigualdade, porém o nível de significância do coeficiente estimado para essa correlação oscila de acordo com a presença dos controles. O sinal desse coeficiente é produto de uma forte e significativa correlação controlada negativa entre crédito direcionado e a variável dependente. Simultaneamente, o crédito livre não apresenta correlação controlada estatisticamente significativa com a variável em questão para todas as especificações testadas, algo que adiciona à discussão na literatura, que não apresenta evidências fortes a respeito dessa relação. Vale lembrar que o crédito, em geral, no contexto de outros países, é equivalente ao crédito livre brasileiro. Além disso, o teste de hipótese de igualdade dos coeficientes de crédito livre e direcionado é fortemente rejeitado (p-valor menor que 1\%) nas regressões 4 a 6 . Isso é um forte indício a favor da ideia de que há uma diferença na atuação dos créditos oriundos de diferentes fontes de recursos.

Novamente, realizando um exercício simples, pode-se checar a relevância econômica dessas estimações. Suponha um aumento de um desvio-padrão do crédito direcionado per capita, ou seja, 3,4 mil reais per capita. Multiplicando esse valor pelo coeficiente estimado na regressão com mais controles $(-0,0066)$, obtém-se -0,0224. Considerando que 
a redução do índice de Gini do período foi de aproximadamente 0,09 , a correlação da redução da desigualdade associada ao crédito direcionado representaria em torno de $25 \%$ da variação média entre os municípios.

Tabela 5 - Regressões MQO: Variação da Pobreza Extrema

\begin{tabular}{|c|c|c|c|c|c|c|c|c|}
\hline \multirow[t]{2}{*}{ tt Variable } & \multicolumn{8}{|l|}{ Var. pobreza } \\
\hline & 1 & 2 & 3 & 4 & 5 & 6 & 7 & 8 \\
\hline & \multicolumn{4}{|c|}{ Crédito Total } & \multicolumn{4}{|c|}{ Crédito Livre e Direcionado } \\
\hline \multirow[t]{2}{*}{ Crédito Total } & $-0.0088 * * *$ & -0.0002 & -0.0019 & -0.0005 & & & & \\
\hline & {$[-4.6119]$} & {$[-0.0863]$} & {$[-0.9964]$} & {$[-0.2932]$} & & & & \\
\hline \multirow[t]{2}{*}{ PIB pc 2003} & $-0.0035^{* * *}$ & -0.0005 & 0.0008 & $0.0016^{* * *}$ & $-0.0036 * * *$ & -0.0005 & 0.0008 & $0.0015^{* * *}$ \\
\hline & {$[-6.2045]$} & {$[-0.8594]$} & [1.4057] & {$[2.7950]$} & {$[-6.5149]$} & {$[-0.8935]$} & [1.3499] & {$[2.6666]$} \\
\hline \multirow[t]{2}{*}{ Escolaridade } & & $-0.0455^{* * *}$ & $-0.0508 * * *$ & $-0.0231 * * *$ & & $-0.0494 * * *$ & $-0.0536 * * *$ & $-0.0269 * * *$ \\
\hline & & {$[-16.9297]$} & {$[-19.1278]$} & {$[-5.7948]$} & & {$[-18.2386]$} & {$[-19.9852]$} & {$[-6.6895]$} \\
\hline \multirow[t]{2}{*}{ Transferências União } & & & $-0.2360 * * *$ & $-0.2161 * * *$ & & & $-0.2237^{* * *}$ & $-0.2062 * * *$ \\
\hline & & & {$[-16.6642]$} & {$[-14.9883]$} & & & {$[-15.7155]$} & {$[-14.2427]$} \\
\hline \multirow[t]{2}{*}{ Valor Bolsa } & & & & $0.0203 * * *$ & & & & $0.0193^{* * *}$ \\
\hline & & & & [9.4177] & & & & [8.9345] \\
\hline \multirow[t]{2}{*}{ Crédito Direcionado } & & & & & $-0.0218 * * *$ & $-0.0203 * * *$ & $-0.0170^{* * *}$ & $-0.0138 * * *$ \\
\hline & & & & & {$[-6.9153]$} & {$[-6.6326]$} & {$[-5.6585]$} & [-4.6179] \\
\hline \multirow[t]{2}{*}{ Crédito Livre } & & & & & $0.0102 * *$ & $0.0307^{* * *}$ & $0.0213^{* * *}$ & $0.0199 * * *$ \\
\hline & & & & & [2.4680] & [7.4216] & [5.2500] & [4.8907] \\
\hline \multirow[t]{2}{*}{ Constant } & $-0.4367 * * *$ & $-0.2769 * * *$ & $-0.1838 * * *$ & $-0.3877^{* * *}$ & $-0.4370^{* * *}$ & $-0.2637 * * *$ & $-0.1787^{* * *}$ & $-0.3726 * * *$ \\
\hline & {$[-106.7781]$} & {$[-27.0441]$} & {$[-15.9527]$} & {$[-15.7284]$} & {$[-107.1275]$} & {$[-25.6353]$} & {$[-15.5322]$} & {$[-15.0787]$} \\
\hline R-squared & 0.024 & 0.079 & 0.131 & 0.148 & 0.03 & 0.092 & 0.138 & 0.153 \\
\hline Liv=Dir & & & & & 0.0000 & 0.0000 & 0.0000 & 0.0000 \\
\hline $\mathrm{N}$ & 4853 & 4853 & 4719 & 4693 & 4853 & 4853 & 4719 & 4693 \\
\hline
\end{tabular}

Tabela 6 - Regressões MQO: Variação da Pobreza

Dependent Variable Var. pobreza2

\begin{tabular}{|c|c|c|c|c|c|c|c|c|}
\hline & 1 & 2 & 3 & 4 & 5 & 6 & 7 & 8 \\
\hline & \multicolumn{4}{|c|}{ Crédito Total } & \multicolumn{4}{|c|}{ Crédito Livre e Direcionado } \\
\hline \multirow[t]{2}{*}{ Crédito Total } & $-0.0223^{* * *}$ & $-0.0096 * * *$ & $-0.0111 * * *$ & $-0.0091 * * *$ & & & & \\
\hline & {$[-16.0089]$} & {$[-7.5684]$} & {$[-9.1907]$} & {$[-8.0616]$} & & & & \\
\hline \multirow[t]{2}{*}{ PIB pc 2003} & $-0.0065 * * *$ & $-0.0021 * * *$ & $-0.0011 * * *$ & 0.0003 & $-0.0065 * * *$ & $-0.0021 * * *$ & $-0.0011 * * *$ & 0.0002 \\
\hline & {$[-15.8308]$} & {$[-5.5320]$} & {$[-2.9562]$} & [0.7382] & {$[-16.0324]$} & {$[-5.6332]$} & {$[-3.0548]$} & [0.5895] \\
\hline \multirow[t]{2}{*}{ Escolaridade } & & $-0.0670 * * *$ & $-0.0712 * * *$ & $-0.0210^{* * *}$ & & $-0.0703 * * *$ & $-0.0735 * * *$ & $-0.0236 * * *$ \\
\hline & & {$[-37.6047]$} & {$[-41.2818]$} & {$[-8.6869]$} & & {$[-39.3344]$} & {$[-42.3331]$} & {$[-9.6595]$} \\
\hline \multirow[t]{2}{*}{ Transferências União } & & & $-0.2206 * * *$ & $-0.1802 * * *$ & & & $-0.2104 * * *$ & $-0.1735^{* * *}$ \\
\hline & & & {$[-23.9881]$} & {$[-20.5821]$} & & & {$[-22.8328]$} & {$[-19.7552]$} \\
\hline \multirow[t]{2}{*}{ Valor Bolsa } & & & & $0.0365 * * *$ & & & & $0.0358 * * *$ \\
\hline & & & & [27.8088] & & & & [27.2887] \\
\hline \multirow[t]{2}{*}{ Crédito Direcionado } & & & & & $-0.0289 * * *$ & $-0.0266 * * *$ & $-0.0235 * * *$ & $-0.0180 * * *$ \\
\hline & & & & & {$[-12.4663]$} & {$[-13.2059]$} & {$[-12.1235]$} & [-9.9228] \\
\hline \multirow[t]{2}{*}{ Crédito Livre } & & & & & $-0.0127 * * *$ & $0.0166 * * *$ & $0.0079 * * *$ & $0.0046^{*}$ \\
\hline & & & & & {$[-4.2083]$} & [6.0618] & [3.0197] & [1.8791] \\
\hline \multirow[t]{2}{*}{ Constant } & $-0.2761 * * *$ & $-0.0408 * * *$ & $0.0444 * * *$ & $-0.3234 * * *$ & $-0.2762 * * *$ & $-0.0296 * * *$ & $0.0487^{* * *}$ & $-0.3133 * * *$ \\
\hline & {$[-92.1833]$} & {$[-6.0020]$} & [5.9401] & {$[-21.6036]$} & {$[-92.3379]$} & {$[-4.3553]$} & [6.5364] & {$[-20.8895]$} \\
\hline R-squared & 0.179 & 0.365 & 0.432 & 0.513 & 0.181 & 0.379 & 0.439 & 0.517 \\
\hline Liv=Dir & & & & & 0.0004 & 0.0000 & 0.0000 & 0.0000 \\
\hline $\mathrm{N}$ & 4853 & 4853 & 4719 & 4693 & 4853 & 4853 & 4719 & 4693 \\
\hline
\end{tabular}


O principal resultado das Tabelas 5 e 6 e mais uma novidade deste trabalho em relação à literatura é o resultado obtido de uma correlação negativa, significativa estatisticamente e robusta entre as variáveis: crédito direcionado per capita e pobreza.

Esse resultado é robusto para diferentes medidas de pobreza: "pobreza extrema" (proporção de pessoas na população do município com renda inferior a um quarto de salário-mínimo) na Tabela 5, ou "pobreza" (proporção de pessoas na população do município com renda inferior a meio de salário-mínimo) na Tabela 6. Além disso, o resultado não é sensível à introdução de diferentes variáveis de controle.

Por outro lado, a variável explicativa crédito livre per capita não apresenta o mesmo grau de robustez. Para as regressões da Tabela 5, há uma correlação controlada significativa e surpreendentemente positiva entre essa variável e a pobreza extrema. Contudo, esse resultado não se sustenta na Tabela 6 , quando é considerada a medida mais abrangente de pobres. Sendo que em algumas especificações há uma correlação positiva e, em outras, a estimação apresenta sinal oposto.

A diferença entre crédito livre e direcionado é ressaltada pelo teste de hipótese de igualdade entre os coeficientes estimados, sendo que essa hipótese é consistentemente rejeitada a 1\%, o que é mais um ponto a favor da diferença das fontes de recursos para a atuação do crédito, sendo que o coeficiente associado ao crédito direcionado sempre é mais negativo, em valor, do que o crédito livre.

Na Tabela 5, o resultado da estimação do coeficiente associado ao crédito total não é conclusivo a favor de uma correlação negativa e essa correlação só é estatisticamente significativa em uma especificação, que é a especificação com menos controles.

Já na Tabela 6, a correlação negativa com o crédito total é a que predomina quando se analisam os resultados das estimações para a medida mais abrangente de pobreza. Essa correlação é negativa e significativa a $1 \%$ em todas as especificações estimadas.

Há alguns destaques entre as variáveis de controle nos resultados apresentados para a variável dependente pobreza em ambas as Tabelas. Em primeiro lugar, Transferências da União para Municípios, cujo coeficiente é negativo e significativo estatisticamente. Isso 
sugere uma relação negativa entre alocação de recursos da União para Municípios e variação da pobreza no período, algo que se espera de um país, no qual um dos objetivos mais relevantes declarados pelo governo é a redução do elevado número de pessoas pobres.

Os coeficientes associados às diferentes formas de mensurar o pagamento de bolsafamília também são consistentemente positivos. Uma possível explicação é a diferença de períodos entre introdução e expansão do programa Bolsa-Família e a mensuração da redução da pobreza. Isto é, os pagamentos podem ter sido destinados a regiões onde havia maior indício de aumento da pobreza ou menor redução da mesma.

Por último, buscando ressaltar a importância econômica das estimações realizadas, considere o desvio-padrão do crédito direcionado de 3,4 mil reais per capita. Multiplicando esse valor pelo coeficiente estimado da regressão com mais controles (0,0138), obtém-se -0,04692. Como observado na seção anterior, a redução da pobreza extrema neste período foi de aproximadamente 0,46 . Assim, a correlação da redução da pobreza extrema associada ao crédito direcionado seria em torno de 10\% (16\%, realizando o mesmo exercício para a estimação com menos controles). Repetindo o raciocínio para a estimação que associa crédito e a variável pobreza (medida mais amplamente) seria obtida uma correlação associada de mais de $18 \%$ da queda dessa medida de pobreza (pouco menos de $30 \%$, realizando o mesmo exercício para a estimação com menos controles).

Tabela 7 - Regressões Painel: Crescimento do PIB per capita

Dependent Variable Cresc PIB pc

\begin{tabular}{|c|c|c|c|c|c|c|c|c|}
\hline & 1 & 2 & 3 & 4 & 5 & 6 & 7 & 8 \\
\hline & \multicolumn{4}{|c|}{ Crédito Total } & \multicolumn{4}{|c|}{ Crédito Livre e Direcionado } \\
\hline \multirow[t]{2}{*}{ Crédito Total } & $0.0307 * * *$ & $0.0127^{* * *}$ & $0.0385^{* * *}$ & $0.0201 * * *$ & & & & \\
\hline & [9.1304] & [3.7026] & [12.5191] & [6.4775] & & & & \\
\hline \multirow[t]{2}{*}{ Dummy } & & $-0.1046 * * *$ & & $-0.1071 * * *$ & & $-0.1046 * * *$ & & $-0.1070 * * *$ \\
\hline & & {$[-17.5833]$} & & {$[-19.9340]$} & & {$[-17.4312]$} & & {$[-19.7307]$} \\
\hline \multirow[t]{2}{*}{ PIB pc 2003} & & & $-0.0553^{* * *}$ & $-0.0558 * * *$ & & & $-0.0554 * * *$ & $-0.0558 * * *$ \\
\hline & & & {$[-31.7122]$} & {$[-33.2493]$} & & & {$[-31.7554]$} & {$[-33.2460]$} \\
\hline \multirow[t]{2}{*}{ Crédito Livre } & & & & & $0.0434^{* * *}$ & $0.0121^{*}$ & $0.0526 * * *$ & $0.0207^{* * *}$ \\
\hline & & & & & [6.5534] & [1.8179] & {$[8.7118]$} & [3.4312] \\
\hline \multirow[t]{2}{*}{ Crédito Direcionado } & & & & & $0.0224 * * *$ & $0.0130 * * *$ & $0.0293 * * *$ & $0.0197^{* * *}$ \\
\hline & & & & & {$[4.4884]$} & {$[2.6570]$} & [6.4237] & [4.4517] \\
\hline \multirow[t]{2}{*}{ Constant } & $0.0430 * * *$ & $0.1148 * * *$ & $0.3598 * * *$ & $0.4361^{* * *}$ & $0.0423 * * *$ & $0.1149 * * *$ & $0.3592^{* * *}$ & $0.4360 * * *$ \\
\hline & [9.1035] & [18.7015] & [33.0772] & [39.1426] & [8.9248] & {$[18.5190]$} & [33.0365] & [39.0445] \\
\hline R-squared & 0.0167 & 0.0751 & 0.1842 & 0.2454 & 0.0177 & 0.0751 & 0.1854 & 0.2454 \\
\hline Liv=Dir & & & & & 0.0259 & 0.9275 & 0.0065 & 0.8994 \\
\hline $\mathrm{N}$ & 9902 & 9902 & 9902 & 9902 & 9902 & 9902 & 9902 & 9902 \\
\hline
\end{tabular}


Os resultados das estimações em painel são apresentados na Tabela 7. Lembrando que na estimação em painel analisa-se apenas o crescimento do PIB per capita como variável dependente, pois os dados de pobreza e desigualdade estão apenas disponíveis em 2000 e 2010. Nessa estimação, o coeficiente que associa o crescimento do PIB per capita e o Crédito Total é positivo e estatisticamente significativo a $1 \%$ nas diferentes especificações. A introdução de uma variável dummy, que é uma forma de controlar os choques agregados de um período em relação ao outro, não altera significativamente as estimações do coeficiente associado à variável crédito total da equação (3).

Entretanto, resultados muito distintos são obtidos em função da introdução dos choques agregados para a equação (4). Sem a presença de dummy, persiste a diferença entre a correlação da variável dependente em relação ao crédito livre e direcionado, ainda que o coeficiente do crédito direcionado estimado não apresente o sinal da estimação em cross section. Isso sugere algum viés nas estimações anteriores. Possivelmente, o crédito direcionado é alocado para regiões, onde já se espera um menor dinamismo ex ante a concessão.

Por outro lado, a introdução de dummy, anula estatisticamente a diferença do valor estimado entre os coeficientes que estimam a correlação entre a variável dependente e os créditos de acordo com a origem. Isso compromete uma conclusão totalmente robusta de diferença da eficiência dos créditos livre e direcionado, apesar de fortes indícios sugeridos pelas estimações anteriores realizadas neste trabalho, pois sugere viés nas estimações obtidas em cross section, dado que essa última estimação considera todas as características fixas do município controladas, bem como os choques macroeconômicos. Dessa forma, algebricamente é possível verificar uma correlação negativa entre a dummy e o crédito direcionado, essa correlação poderia sugerir uma mudança de atuação das concessões ou do efeito dos contratos de crédito direcionado no segundo período (20062008) em relação ao primeiro (2003-2005), uma hipótese que não poderá ser confirmada com os dados disponíveis para a execução deste trabalho.

Outra possibilidade é que as correlações sejam diferentes de acordo com o nível de renda dos municípios. Essa hipótese será testada na próxima seção. 


\section{Robustez}

O objetivo dessa seção é checar a sensibilidade dos resultados obtidos em relação ao tamanho dos municípios. A métrica para "tamanho dos municípios" será o nível do PIB per capita em 2003, para as regressões cross section e, tanto para 2003 como para 2006, para as regressões em painel de efeitos fixos. Dessa forma, aproveitando-se do elevado tamanho da amostra, pretende-se contribuir para entender se o tamanho do município afeta as correlações controladas entre o crédito e as variáveis de desenvolvimento abordadas até aqui e se houve influência de outliers ou de uma faixa específica da distribuição de renda dos municípios para os principais resultados apresentados na seção anterior.

As Tabelas $8 \mathrm{a}$ e $8 \mathrm{~b}$ apresentam resultados para as especificações com todos os controles (equivalentes às colunas 3 e 6 da Tabela 3) para diversos cortes realizados na amostra das equações 1 e 2, quando a variável dependente em questão é o crescimento real do PIB per capita.

\section{Tabela 8a - Regressões MQO por percentil: PIB per capita x Crédito Total}

\begin{tabular}{|c|c|c|c|c|c|c|c|c|c|}
\hline Percentile & $100 \%$ & $>5 \%$ & $>10 \%$ & $<50 \%$ & $>50 \%$ & $<90 \%$ & $<95 \%$ & 5 ב $95 \%$ & \\
\hline Regression & 3 & 3 & 3 & 3 & 3 & 3 & 3 & 3 & 3 \\
\hline \multirow[t]{2}{*}{ Crédito Total } & 0.0002 & -0.0004 & -0.0007 & $0.2755^{* * *}$ & -0.0057 & $0.0397 * * *$ & $0.0219 * * *$ & $0.0205^{* * *}$ & $0.0368 * * *$ \\
\hline & {$[0.0546]$} & {$[-0.0967]$} & {$[-0.1474]$} & [10.9071] & {$[-1.2042]$} & [4.4292] & [3.1981] & [2.9443] & [3.9475] \\
\hline \multirow[t]{2}{*}{ PIB pc 2003} & $-0.0085^{* * *}$ & $-0.0084 * * *$ & $-0.0084 * * *$ & $-0.0885^{* * *}$ & $-0.0057^{* * *}$ & $-0.0425 * * *$ & $-0.0330 * * *$ & $-0.0325^{* * *}$ & $-0.0414^{* * *}$ \\
\hline & {$[-6.2676]$} & {$[-6.1336]$} & {$[-5.9580]$} & {$[-6.2428]$} & {$[-3.8590]$} & {$[-9.2223]$} & [-9.0989] & {$[-8.8035]$} & {$[-8.4813]$} \\
\hline \multirow[t]{2}{*}{ Escolaridade } & $-0.0216 * * *$ & $-0.0148^{* *}$ & -0.0106 & -0.0027 & -0.0006 & 0.0073 & 0.0063 & 0.0128 & $0.0164^{*}$ \\
\hline & {$[-3.4100]$} & {$[-2.2150]$} & [-1.4777] & {$[-0.2141]$} & {$[-0.0548]$} & [0.8470] & [0.7983] & [1.5329] & [1.7170] \\
\hline \multirow[t]{2}{*}{ Transferências Uniãc } & -0.035 & -0.0217 & -0.0126 & $0.2032 * * *$ & -0.0524 & 0.0581 & 0.0445 & 0.0562 & $0.0744 *$ \\
\hline & [-1.0359] & {$[-0.6301]$} & {$[-0.3543]$} & [3.3766] & [-1.1909] & [1.5191] & [1.2304] & [1.5240] & [1.8453] \\
\hline \multirow[t]{2}{*}{ Constant } & $0.3435^{* * *}$ & $0.3062^{* * *}$ & $0.2812 * * *$ & $0.3509 * * *$ & $0.2111 * * *$ & $0.3184 * * *$ & $0.3021 * * *$ & $0.2666^{* * *}$ & $0.2675 * * *$ \\
\hline & [12.5006] & [10.2985] & [8.6793] & [9.3040] & [3.3983] & [10.5523] & [10.3945] & [8.4957] & [7.5177] \\
\hline R-squared & 0.021 & 0.017 & 0.015 & 0.053 & 0.009 & 0.028 & 0.028 & 0.024 & 0.021 \\
\hline $\mathrm{N}$ & 4719 & 4511 & 4287 & 2299 & 2420 & 4241 & 4484 & 4276 & 3809 \\
\hline
\end{tabular}

OBS.: Percentile se refere a qual parte da amostra foi utilizada para obtenção das estimativas dos coeficientes apresentados, considerando a variável nível de renda per capita em 2003 
Tabela 8b - Regressões MQO por percentil: PIB per capita x Crédito Origem

\begin{tabular}{|c|c|c|c|c|c|c|c|c|c|}
\hline Percentile & $100 \%$ & $>5 \%$ & $>10 \%$ & $<50 \%$ & $>50 \%$ & $<90 \%$ & $<95 \%$ & 5 a $95 \%$ & 10 a $90 \%$ \\
\hline Regression & 6 & 6 & 6 & 6 & 6 & 6 & 6 & 6 & 6 \\
\hline \multirow[t]{2}{*}{ PIB pc 2003} & $-0.0086^{* * *}$ & $-0.0085^{* * *}$ & $-0.0084^{* * *}$ & $-0.0823 * * *$ & $-0.0058 * * *$ & $-0.0403^{* * *}$ & $-0.0320 * * *$ & $-0.0316 * * *$ & $-0.0393^{* * *}$ \\
\hline & {$[-6.3283]$} & {$[-6.1897]$} & {$[-6.0128]$} & {$[-5.8919]$} & {$[-3.9421]$} & {$[-8.6707]$} & {$[-8.8178]$} & {$[-8.5345]$} & {$[-7.9785]$} \\
\hline \multirow[t]{2}{*}{ Escolaridade } & $-0.0265^{* * *}$ & $-0.0199 * * *$ & $-0.0158 * *$ & -0.02 & -0.0072 & 0.0005 & 0.0002 & 0.0066 & 0.0094 \\
\hline & {$[-4.1395]$} & {$[-2.9330]$} & {$[-2.1921]$} & {$[-1.6100]$} & {$[-0.6154]$} & {$[0.0511]$} & {$[0.0258]$} & {$[0.7801]$} & [0.9617] \\
\hline \multirow[t]{2}{*}{ Transferências União } & -0.0129 & -0.0008 & 0.0077 & $0.2430 * * *$ & -0.043 & $0.0732 *$ & $0.0620 *$ & $0.0727 *$ & $0.0883^{* *}$ \\
\hline & {$[-0.3797]$} & {$[-0.0230]$} & [0.2162] & [4.0935] & {$[-0.9741]$} & [1.9029] & [1.7055] & [1.9581] & [2.1785] \\
\hline \multirow[t]{2}{*}{ Crédito Direcionado } & $-0.0268 * * *$ & $-0.0265^{* * *}$ & $-0.0263 * * *$ & -0.0008 & $-0.0202 * * *$ & 0.0018 & -0.0077 & -0.0078 & 0.0014 \\
\hline & {$[-3.7426]$} & {$[-3.6585]$} & {$[-3.5624]$} & {$[-0.0201]$} & {$[-2.6307]$} & [0.1273] & {$[-0.7550]$} & {$[-0.7509]$} & [0.0934] \\
\hline \multirow[t]{2}{*}{ Crédito Livre } & $0.0417^{* * *}$ & $0.0396 * * *$ & $0.0388^{* * *}$ & $0.6212^{* * *}$ & 0.0169 & $0.0922 * * *$ & $0.0671 * * *$ & $0.0636^{* * *}$ & $0.0861^{* * *}$ \\
\hline & [4.3017] & [4.0333] & [3.8673] & [13.4224] & [1.6000] & [5.2847] & [5.0047] & [4.6753] & [4.7394] \\
\hline \multirow[t]{2}{*}{ Constant } & $0.3528 * * *$ & $0.3167^{* * *}$ & $0.2932 * * *$ & $0.3656^{* * *}$ & $0.2382 * * *$ & $0.3288^{* * *}$ & $0.3127^{* * *}$ & $0.2780^{* * *}$ & $0.2792^{* * *}$ \\
\hline & [12.8356] & [10.6423] & [9.0373] & [9.8440] & [3.7768] & [10.8571] & [10.7308] & [8.8299] & [7.8129] \\
\hline R-squared & 0.026 & 0.022 & 0.019 & 0.084 & 0.011 & 0.03 & 0.031 & 0.027 & 0.023 \\
\hline Liv=Dir & 0.0000 & 0.000 & 0.0000 & 0.0000 & 0.0165 & 0.0005 & 0.0001 & 0.0002 & 0.0016 \\
\hline $\mathrm{N}$ & 4719 & 4511 & 4287 & 2299 & 2420 & 4241 & 4484 & 4276 & 3809 \\
\hline
\end{tabular}

Em primeiro lugar, é importante ressaltar que quando os municípios dos percentis mais baixos de PIB per capita foram excluídos, os resultados praticamente não se alteraram. Por outro lado, isso não ocorre quando os municípios excluídos são aqueles dos percentis mais elevados. A mudança ao excluir os maiores municípios tem como resultado o aumento da estimativa do crédito total e do crédito livre e resulta em estimativas não significativas para o crédito direcionado. Dessa forma, os resultados para o crédito livre se tornaram mais próximos dos obtidos em painel e alinhados com a literatura internacional abordada anteriormente.

Além disso, o teste estatístico para a diferença entre os coeficientes estimados para as fontes de recursos de crédito rejeita a hipótese de igualdade a menos de $2 \%$ em todas as amostras testadas.

Resultados semelhantes aos da exclusão dos percentis mais elevados foram obtidos quando excluídos os dois extremos da distribuição de renda per capita. Esses resultados sugerem que os municípios de renda per capita dos percentis mais elevados afetaram mais intensamente os principais resultados discutidos anteriormente e que os percentis mais baixos tiveram pouco impacto naquelas estimações.

Esses novos resultados podem ser consequência da dinâmica de muitos municípios que estão nos percentis mais elevados de renda per capita. Há casos de municípios com 
população pequena e que possuem uma grande atividade produtiva que, ou é pouco intensiva em trabalho, ou utiliza mão-de-obra de municípios vizinhos.

Um padrão semelhante ao obtido nas Tabelas $8 \mathrm{a}$ e $8 \mathrm{~b}$ foi observado nas estimações (equivalentes às colunas 4 e 8 da Tabela 7) por painel de efeito fixo apresentadas pelas Tabelas $9 a$ e $9 b$.

Tabela 9a - Regressões Painel por percentil: PIB per capita x Crédito Total

\begin{tabular}{|c|c|c|c|c|c|c|c|c|c|}
\hline pendent Variable & Cresc PIB pc & Painel & & & & & & & \\
\hline Percentile & $100 \%$ & $>5 \%$ & $>10 \%$ & $<50 \%$ & $>50 \%$ & $<90 \%$ & $<95 \%$ & 5 а $95 \%$ & 10 a $90 \%$ \\
\hline Regression & 4 & 4 & 4 & 4 & 4 & 4 & 4 & 4 & 4 \\
\hline Créditc & $\begin{array}{c}0.0201^{* * *} \\
{[6.4775]}\end{array}$ & $\begin{array}{c}0.0205 * * * \\
{[6.4970]}\end{array}$ & $\begin{array}{c}0.0206^{* * *} \\
{[6.3687]}\end{array}$ & $\begin{array}{c}0.0178 \\
{[1.5732]}\end{array}$ & $\begin{array}{c}0.0113^{* * *} \\
{[4.0244]}\end{array}$ & $\begin{array}{c}0.0359 * * * \\
{[6.0897]}\end{array}$ & $\begin{array}{c}0.0322^{* * *} \\
{[6.9722]}\end{array}$ & $\begin{array}{c}0.0336^{* * *} \\
{[7.1143]}\end{array}$ & $\begin{array}{c}0.0389^{* * *} \\
{[6.2616]}\end{array}$ \\
\hline Dummy & $\begin{array}{c}-0.1071^{* * *} \\
{[-19.9340]}\end{array}$ & $\begin{array}{c}-0.1037^{* * *} \\
{[-18.3857]}\end{array}$ & $\begin{array}{c}-0.1032^{* * *} \\
{[-17.3467]}\end{array}$ & $\begin{array}{c}-0.1585^{* * *} \\
{[-31.5111]}\end{array}$ & $\begin{array}{c}-0.1228 * * * \\
{[-17.9173]}\end{array}$ & $\begin{array}{c}-0.1143^{* * *} \\
{[-20.7189]}\end{array}$ & $\begin{array}{c}-0.1108 * * * \\
{[-21.1712]}\end{array}$ & $\begin{array}{c}-0.1061^{* * *} \\
{[-19.2329]}\end{array}$ & $\begin{array}{c}-0.1063 * * * \\
{[-17.1176]}\end{array}$ \\
\hline $\mathrm{PIB} p \mathrm{p}$ & $\begin{array}{c}-0.0558^{* * *} \\
{[-33.2493]}\end{array}$ & $\begin{array}{c}-0.0557^{* * *} \\
{[-32.6045]}\end{array}$ & $\begin{array}{c}-0.0555^{* * *} \\
{[-31.8918]}\end{array}$ & $\begin{array}{c}-0.3959 * * * \\
{[-33.8677]}\end{array}$ & $\begin{array}{c}-0.0516^{* * *} \\
{[-34.7890]}\end{array}$ & $\begin{array}{c}-0.1897 * * * \\
{[-33.9841]}\end{array}$ & $\begin{array}{c}-0.1597 * * * \\
{[-37.4916]}\end{array}$ & $\begin{array}{c}-0.1590 * * * \\
{[-36.6658]}\end{array}$ & $\begin{array}{c}-0.1868 * * * \\
{[-32.0509]}\end{array}$ \\
\hline Constant & $\begin{array}{l}0.4361^{* * *} \\
{[39.1426]}\end{array}$ & $\begin{array}{l}0.4438^{* * *} \\
{[37.3906]}\end{array}$ & $\begin{array}{l}0.4552^{* * *} \\
{[35.9306]}\end{array}$ & $\begin{array}{l}1.1269 * * * \\
{[37.6695]}\end{array}$ & $\begin{array}{l}0.5751^{* * *} \\
{[36.6745]}\end{array}$ & $\begin{array}{l}0.9287 * * * \\
{[36.1681]}\end{array}$ & $\begin{array}{l}0.8609 * * * \\
{[40.1547]}\end{array}$ & $\begin{array}{l}0.8840^{* * *} \\
{[38.6739]}\end{array}$ & $\begin{array}{l}0.9796 * * * \\
{[33.2528]}\end{array}$ \\
\hline R-squared & 0.2454 & 0.2439 & 0.2449 & 0.4030 & 0.4104 & 0.2859 & 0.3083 & 0.3072 & 0.2833 \\
\hline & 9902 & 9320 & 8744 & 4591 & 4725 & 8672 & 9250 & 8668 & 7514 \\
\hline
\end{tabular}

Tabela 9b - Regressões Painel por percentil: PIB per capita x Crédito Origem

\begin{tabular}{|c|c|c|c|c|c|c|c|c|c|}
\hline Dependent Variable & Cresc PIB pc & Painel & & & & & & & \\
\hline Percentile & $100 \%$ & $>5 \%$ & $>10 \%$ & $<50 \%$ & $>50 \%$ & $<90 \%$ & $<95 \%$ & 5 а $95 \%$ & 10 a $90 \%$ \\
\hline Regression & 8 & 8 & 8 & 8 & 8 & 8 & 8 & 8 & 8 \\
\hline \multirow[t]{2}{*}{ Dummy } & $-0.1070 * * *$ & $-0.1036 * * *$ & $-0.1030 * * *$ & $-0.1591^{* * *}$ & $-0.1261^{* * *}$ & $-0.1135^{* * *}$ & $-0.1108^{* * *}$ & $-0.1060 * * *$ & $-0.1054 * * *$ \\
\hline & [-19.7307] & [-18.1835] & {$[-17.1468]$} & {$[-31.3835]$} & [-18.1932] & {$[-20.5831]$} & [-21.1571] & {$[-19.2207]$} & [-16.9861] \\
\hline \multirow[t]{2}{*}{ PIB pc } & $-0.0558 * * *$ & $-0.0557 * * *$ & $-0.0555^{* * *}$ & $-0.3955 * * *$ & $-0.0516^{* * *}$ & $-0.1924 * * *$ & $-0.1602^{* * *}$ & $-0.1595 * * *$ & $-0.1894^{* * *}$ \\
\hline & {$[-33.2460]$} & {$[-32.6015]$} & {$[-31.8886]$} & [-33.8262] & [-34.8303] & [-34.1649] & [-37.2117] & {$[-36.3835]$} & [-32.2139] \\
\hline \multirow[t]{2}{*}{ Crédito Livre } & $0.0207^{* * *}$ & $0.0214^{* * *}$ & $0.0215^{* * *}$ & 0.004 & -0.0027 & $0.0693^{* * *}$ & $0.0382^{* * *}$ & $0.0389 * * *$ & $0.0711^{* * *}$ \\
\hline & [3.4312] & [3.4828] & [3.4194] & [0.2203] & {$[-0.5032]$} & {$[6.0188]$} & [4.2398] & [4.2483] & [5.9145] \\
\hline \multirow[t]{2}{*}{ Crédito Direcionado } & $0.0197^{* * *}$ & $0.0200 * * *$ & $0.0200 * * *$ & $0.0309^{*}$ & $0.0194 * * *$ & -0.0002 & $0.0254^{* *}$ & $0.0274 * * *$ & 0.004 \\
\hline & {$[4.4517]$} & {$[4.4418]$} & {$[4.3615]$} & [1.7330] & [4.9697] & {$[-0.0183]$} & [2.5300] & {$[2.6877]$} & [0.3172] \\
\hline \multirow[t]{2}{*}{ Constant } & $0.4360^{* * *}$ & $0.4437^{* * *}$ & $0.4551^{* * *}$ & $1.1267^{* * *}$ & $0.5786^{* * *}$ & $0.9436^{* * *}$ & $0.8642^{* * *}$ & $0.8871^{* * *}$ & $0.9955^{* * *}$ \\
\hline & [39.0445] & [37.2911] & [35.8326] & [37.6634] & {$[36.8561]$} & [36.2602] & [39.5346] & [38.0591] & [33.3375] \\
\hline R-squared & 0.2454 & 0.2439 & 0.2449 & 0.4032 & 0.4127 & 0.2877 & 0.3084 & 0.3073 & 0.2852 \\
\hline Liv=Dir & 0.8994 & 0.8629 & 0.8626 & 0.3423 & 0.0029 & 0.0007 & 0.4413 & 0.4959 & 0.0018 \\
\hline $\mathrm{N}$ & 9902 & 9320 & 8744 & 4591 & 4725 & 8672 & 9250 & 8668 & 7514 \\
\hline
\end{tabular}

${ }^{*} p<.10,{ }^{* *} p<.05,{ }^{* * *} p<.01$, t-statistic in brackets.

Esses resultados mais uma vez sugerem, com algumas ressalvas, que a correlação positiva, entre o crédito direcionado e o crescimento, apresentada anteriormente está sendo causada pelos municípios que estão nos percentis mais elevados de renda per capita. Entretanto, quando são desconsiderados apenas os municípios que estão no quinto percentil superior, a relação permanece positiva e a diferença deste coeficiente para a estimação da variável crédito livre não é mais estatisticamente significativa. 
Em seguida, as Tabelas 10a e 10b apresentam os resultados das estimações das regressões 3 e 6 respectivamente referentes às equações 1 e 2 para a variável dependente variação do índice de Gini.

\section{Tabela 10a - Regressões MQO por percentil: Gini x Crédito Total}

\begin{tabular}{|c|c|c|c|c|c|c|c|c|c|}
\hline Dependent Variable & Gini & Cross Section & & & & & & & \\
\hline Percentile & $100 \%$ & $>5 \%$ & $>10 \%$ & $<50 \%$ & $>50 \%$ & $<90 \%$ & $<95 \%$ & 5 a $95 \%$ & 10 a $90 \%$ \\
\hline Regression & 3 & 3 & 3 & 3 & 3 & 3 & 3 & 3 & 3 \\
\hline \multirow[t]{2}{*}{ Crédito Total } & $-0.0022^{* *}$ & $-0.0022^{* *}$ & $-0.0022 * *$ & 0.003 & $-0.0027^{* *}$ & $-0.0039 *$ & $-0.0034 * *$ & $-0.0036^{* *}$ & $-0.0042 * *$ \\
\hline & {$[-2.0740]$} & {$[-2.1150]$} & {$[-2.1030]$} & {$[0.4652]$} & {$[-2.5091]$} & {$[-1.8721]$} & {$[-2.0880]$} & {$[-2.1902]$} & {$[-1.9822]$} \\
\hline \multirow[t]{2}{*}{ PIB pc 2003} & -0.0002 & -0.0001 & -0.0001 & $-0.0130 * * *$ & 0.0001 & $-0.0029 * * *$ & -0.0009 & -0.0006 & $-0.0022 * *$ \\
\hline & {$[-0.5544]$} & {$[-0.4566]$} & {$[-0.3738]$} & {$[-3.5619]$} & {$[0.3658]$} & {$[-2.6358]$} & {$[-1.0138]$} & {$[-0.6972]$} & {$[-2.0173]$} \\
\hline \multirow[t]{2}{*}{ Escolaridade } & $-0.0085 * * *$ & $-0.0071^{* * *}$ & $-0.0065^{* * *}$ & $-0.0088^{* * *}$ & $0.0064^{* *}$ & $-0.0069 * * *$ & $-0.0083^{* * *}$ & ${ }^{*}-0.0072^{* * *}$ & $-0.0060 * * *$ \\
\hline & {$[-5.6173]$} & {$[-4.4709]$} & {$[-3.9566]$} & {$[-2.7296]$} & [2.4618] & {$[-3.3752]$} & {$[-4.3575]$} & {$[-3.6812]$} & {$[-2.7841]$} \\
\hline \multirow[t]{2}{*}{ Transferências União } & $-0.0179 * *$ & $-0.0137 *$ & -0.0121 & -0.0064 & 0.0045 & -0.0051 & -0.0117 & -0.008 & -0.001 \\
\hline & {$[-2.2182]$} & {$[-1.6914]$} & {$[-1.4740]$} & {$[-0.4146]$} & {$[0.4517]$} & {$[-0.5673]$} & {$[-1.3575]$} & {$[-0.9283]$} & {$[-0.1063]$} \\
\hline \multirow[t]{2}{*}{ Constant } & $-0.0449 * * *$ & $-0.0538 * * *$ & $-0.0574 * * *$ & -0.0139 & $-0.1317^{* * *}$ & $-0.0437 * * *$ & $-0.0440 * * *$ & $-0.0521 * * *$ & $-0.0529 * * *$ \\
\hline & {$[-6.8476]$} & {$[-7.6839]$} & {$[-7.6533]$} & {$[-1.4293]$} & {$[-9.3355]$} & {$[-6.1577]$} & {$[-6.3559]$} & {$[-7.0724]$} & {$[-6.5541]$} \\
\hline R-squared & 0.015 & 0.01 & 0.008 & 0.022 & 0.003 & 0.023 & 0.018 & 0.013 & 0.015 \\
\hline $\mathrm{N}$ & 4719 & 4511 & 4287 & 2299 & 2420 & 4241 & 4484 & 4276 & 3809 \\
\hline
\end{tabular}

\section{Tabela 10b - Regressões MQO por percentil: Gini x Crédito Origem}

\begin{tabular}{|c|c|c|c|c|c|c|c|c|c|}
\hline Dependent Variable & Gini & Cross Section & & & & & & & \\
\hline Percentile & $100 \%$ & $>5 \%$ & $>10 \%$ & $<50 \%$ & $>50 \%$ & $<90 \%$ & $<95 \%$ & 5 a $95 \%$ & 10 a $90 \%$ \\
\hline Regression & 6 & 6 & 6 & 6 & 6 & 6 & 6 & 6 & 6 \\
\hline \multirow[t]{2}{*}{ PIB pc 2003} & -0.0002 & -0.0002 & -0.0001 & $-0.0129 * * *$ & 0.0001 & $-0.0028^{* * *}$ & -0.0007 & -0.0004 & $-0.0022^{* *}$ \\
\hline & {$[-0.5867]$} & {$[-0.4873]$} & {$[-0.4047]$} & {$[-3.5254]$} & [0.2974] & {$[-2.6035]$} & {$[-0.8291]$} & {$[-0.5128]$} & {$[-1.9878]$} \\
\hline \multirow[t]{2}{*}{ Escolaridade } & $-0.0093 * * *$ & $-0.0079 * * *$ & $-0.0074^{* * *}$ & $-0.0091 * * *$ & $0.0051^{*}$ & $-0.0069 * * *$ & $-0.0092 * * *$ & $-0.0082 * * *$ & $-0.0061 * * *$ \\
\hline & {$[-6.0773]$} & {$[-4.9413]$} & {$[-4.4359]$} & {$[-2.7934]$} & [1.9233] & {$[-3.3031]$} & {$[-4.7855]$} & {$[-4.1222]$} & {$[-2.7289]$} \\
\hline \multirow[t]{2}{*}{ Transferências União } & $-0.0143^{*}$ & -0.0103 & -0.0087 & -0.0057 & 0.0063 & -0.005 & -0.0089 & -0.0053 & -0.0009 \\
\hline & {$[-1.7542]$} & {$[-1.2522]$} & {$[-1.0519]$} & {$[-0.3662]$} & [0.6291] & {$[-0.5576]$} & {$[-1.0251]$} & {$[-0.6104]$} & {$[-0.0975]$} \\
\hline \multirow[t]{2}{*}{ Crédito Direcionado } & $-0.0066 * * *$ & $-0.0066 * * *$ & $-0.0065^{* * *}$ & -0.0021 & $-0.0055^{* * *}$ & -0.0041 & $-0.0081^{* * *}$ & $-0.0082 * * *$ & -0.0044 \\
\hline & [-3.8796] & {$[-3.8547]$} & {$[-3.8170]$} & {$[-0.1982]$} & {$[-3.1340]$} & {$[-1.2355]$} & [-3.3459] & [-3.3949] & {$[-1.3238]$} \\
\hline \multirow[t]{2}{*}{ Crédito Livre } & $0.0046^{* *}$ & $0.0044^{*}$ & $0.0044^{*}$ & 0.0094 & 0.0016 & -0.0038 & 0.0038 & 0.0036 & -0.0039 \\
\hline & [1.9907] & [1.9160] & [1.8883] & [0.7758] & [0.6677] & {$[-0.9141]$} & [1.1867] & [1.1128] & {$[-0.9519]$} \\
\hline \multirow[t]{2}{*}{ Constant } & $-0.0434 * * *$ & $-0.0521^{* * *}$ & $-0.0554 * * *$ & -0.0136 & $-0.1265^{* * *}$ & $-0.0436 * * *$ & $-0.0423 * * *$ & $-0.0502 * * *$ & $-0.0528 * * *$ \\
\hline & {$[-6.6068]$} & [-7.4209] & {$[-7.3672]$} & [-1.3999] & {$[-8.8290]$} & {$[-6.1225]$} & {$[-6.0882]$} & {$[-6.7872]$} & {$[-6.5104]$} \\
\hline R-squared & 0.017 & 0.012 & 0.011 & 0.022 & 0.004 & 0.022 & 0.019 & 0.014 & 0.015 \\
\hline Liv=Dir & 0.0010 & 0.001 & 0.0014 & 0.5330 & 0.0443 & 0.9566 & 0.0088 & 0.0095 & 0.9401 \\
\hline $\mathrm{N}$ & 4719 & 4511 & 4287 & 2299 & 2420 & 4241 & 4484 & 4276 & 3809 \\
\hline
\end{tabular}

Mais uma vez, surge um padrão semelhante em relação ao tamanho dos municípios e a sensibilidade dos resultados. Isto é, quando os percentis mais baixos de PIB per capita são desconsiderados, a mudança dos resultados discutidos é marginal e quase imperceptível. Entretanto, a exclusão dos municípios de PIB per capita do percentil 5\% mais elevado leva a um aumento do valor absoluto dos coeficientes do crédito total e do direcionado. Já o crédito livre perde significância, mas com pequena mudança no valor da estimação. $O$ 
resultado muda marginalmente quando a exclusão é tanto dos $5 \%$ superiores como dos $5 \%$ inferiores. Os resultados obtidos para o crédito direcionado perdem significância ao excluir os dados com percentil de PIB per capita $10 \%$ superiores e $10 \%$ inferiores. Isso sugere que a maior influência nos resultados estimados pode estar concentrada entre os municípios do nonagésimo ao nonagésimo quinto percentil de renda per capita.

Logo a seguir, as Tabelas 11a, 11b, 12a e 12b apresentam os resultados das estimações das regressões 4 e 8 respectivamente referentes às equações 1 e 2 para a variável dependente variação da pobreza, mensurada pelos indicadores anteriormente apresentados.

Tabela 11a - Regressões MQO por percentil: Pobreza Extrema x Crédito Total

\begin{tabular}{|c|c|c|c|c|c|c|c|c|c|}
\hline Dependent Variable & Pobreza & Cross Section & & & & & & & \\
\hline Percentile & $100 \%$ & $>5 \%$ & $>10 \%$ & $<50 \%$ & $>50 \%$ & $<90 \%$ & $<95 \%$ & 5 а $95 \%$ & 10 a $90 \%$ \\
\hline Regression & 4 & 4 & 4 & 4 & 4 & 4 & 4 & 4 & 4 \\
\hline \multirow[t]{2}{*}{ Crédito Total } & -0.0005 & -0.0006 & -0.0007 & $-0.0172^{* *}$ & -0.0013 & $-0.0130 * * *$ & $-0.0089 * * *$ & $*-0.0091 * * *$ & $-0.0136^{* * *}$ \\
\hline & {$[-0.2932]$} & {$[-0.3226]$} & [-0.3399] & {$[-2.2253]$} & {$[-0.5691]$} & {$[-3.7271]$} & [-3.2499] & {$[-3.2994]$} & [-3.7453] \\
\hline \multirow[t]{2}{*}{ PIB pc 2003} & $0.0016^{* * *}$ & $0.0017^{* * *}$ & $0.0017^{* * *}$ & $-0.0251 * * *$ & $0.0022^{* * *}$ & $-0.0052^{* * *}$ & -0.002 & -0.0015 & $-0.0038^{*}$ \\
\hline & {$[2.7950]$} & [2.8553] & [2.8819] & {$[-5.1791]$} & [3.0559] & {$[-2.6723]$} & {$[-1.3338]$} & {$[-0.9829]$} & {$[-1.8718]$} \\
\hline \multirow[t]{2}{*}{ Escolaridade } & $-0.0231 * * *$ & $-0.0202 * * *$ & $-0.0186^{* * *}$ & $-0.0421 * * *$ & 0.0034 & $-0.0275^{* * *}$ & $-0.0238 * * *$ & k $-0.0214^{* * *}$ & $-0.0246 * * *$ \\
\hline & {$[-5.7948]$} & {$[-4.8474]$} & {$[-4.2787]$} & {$[-9.7763]$} & [0.5097] & {$[-6.6059]$} & {$[-5.8803]$} & {$[-5.0595]$} & [-5.3949] \\
\hline \multirow[t]{2}{*}{ Transferências União } & $-0.2161 * * *$ & $-0.2097 * * *$ & $-0.2064^{* * *}$ & $-0.1796 * * *$ & $-0.1751^{* * *}$ & $-0.2100 * * *$ & $-0.2178 * * *$ & ${ }^{*}-0.2127^{* * *}$ & $-0.2048 * * *$ \\
\hline & [-14.9883] & {$[-14.2108]$} & {$[-13.6116]$} & {$[-9.6879]$} & {$[-8.1073]$} & {$[-13.9628]$} & {$[-14.9286]$} & {$[-14.2481]$} & {$[-12.9213]$} \\
\hline \multirow[t]{2}{*}{ Valor Bolsa } & $0.0203^{* * *}$ & $0.0208^{* * *}$ & $0.0208 * * *$ & 0.0032 & $0.0107^{* *}$ & $0.0122 * * *$ & $0.0159 * * *$ & $0.0165^{* * *}$ & $0.0131 * * *$ \\
\hline & [9.4177] & {$[9.2247]$} & [8.7719] & [1.3882] & [2.1498] & [5.2449] & [7.1129] & [7.0882] & [5.1483] \\
\hline \multirow[t]{2}{*}{ Constant } & $-0.3877^{* * *}$ & $-0.4055^{* * *}$ & $-0.4155^{* * *}$ & $-0.1625^{* * *}$ & $-0.5258^{* * *}$ & $-0.3016 * * *$ & $-0.3438^{* * *}$ & $-0.3615^{* * *}$ & $-0.3275^{* * *}$ \\
\hline & {$[-15.7284]$} & {$[-15.7202]$} & {$[-15.4648]$} & {$[-6.1958]$} & {$[-12.3162]$} & {$[-11.8195]$} & {$[-13.9240]$} & {$[-13.9432]$} & {$[-11.6044]$} \\
\hline R-squared & 0.148 & 0.13 & 0.114 & 0.226 & 0.033 & 0.186 & 0.176 & 0.156 & 0.148 \\
\hline $\mathrm{N}$ & 4693 & 4485 & 4262 & 2289 & 2404 & 4219 & 4462 & 4254 & 3788 \\
\hline
\end{tabular}


Tabela 11b - Regressões MQO por percentil: Pobreza Extrema x Crédito Origem

\begin{tabular}{|c|c|c|c|c|c|c|c|c|c|}
\hline ependent Variable & Pobreza & Cross Section & & & & & & & \\
\hline Percentile & $100 \%$ & $>5 \%$ & $>10 \%$ & $<50 \%$ & $>50 \%$ & $<90 \%$ & $<95 \%$ & 5 a $95 \%$ & 10 a $90 \%$ \\
\hline Regression & 8 & 8 & 8 & 8 & 8 & 8 & 8 & 8 & 8 \\
\hline \multirow[t]{2}{*}{ PIB pc 2003} & $0.0015^{* * *}$ & $0.0016^{* * *}$ & $0.0016^{* * *}$ & $-0.0251 * * *$ & $0.0021^{* * *}$ & $-0.0042^{* *}$ & -0.0016 & -0.0011 & -0.0028 \\
\hline & [2.6666] & [2.7323] & [2.7641] & {$[-5.1919]$} & [2.9321] & {$[-2.1332]$} & {$[-1.0430]$} & {$[-0.6952]$} & {$[-1.3550]$} \\
\hline \multirow[t]{2}{*}{ Escolaridade } & $-0.0269 * * *$ & $-0.0242 * * *$ & $-0.0227^{* * *}$ & $-0.0418 * * *$ & -0.0013 & $-0.0320 * * *$ & $-0.0292 * * *$ & $-0.0271 * * *$ & $-0.0295^{* * *}$ \\
\hline & {$[-6.6895]$} & {$[-5.7431]$} & {$[-5.1642]$} & {$[-9.5785]$} & {$[-0.1966]$} & {$[-7.5409]$} & {$[-7.1290]$} & {$[-6.3128]$} & {$[-6.3322]$} \\
\hline \multirow[t]{2}{*}{ Transferências União } & $-0.2062 * * *$ & $-0.2001^{* * *}$ & $-0.1971^{* * *}$ & $-0.1804^{* * *}$ & $-0.1682^{* * *}$ & $-0.2014 * * *$ & $-0.2057^{* * *}$ & $-0.2010^{* * *}$ & $-0.1963 * * *$ \\
\hline & {$[-14.2427]$} & {$[-13.5162]$} & {$[-12.9538]$} & {$[-9.6966]$} & {$[-7.7746]$} & {$[-13.3391]$} & {$[-14.0732]$} & {$[-13.4441]$} & {$[-12.3519]$} \\
\hline \multirow[t]{2}{*}{ Valor Bolsa } & $0.0193^{* * *}$ & $0.0197 * * *$ & $0.0197^{* * *}$ & 0.0032 & $0.0107^{* *}$ & $0.0116^{* * *}$ & $0.0149 * * *$ & $0.0154 * * *$ & $0.0124^{* * *}$ \\
\hline & [8.9345] & [8.7447] & [8.3151] & [1.4044] & [2.1553] & [4.9970] & [6.6839] & [6.6525] & [4.8927] \\
\hline \multirow[t]{2}{*}{ Crédito Direcionado } & $-0.0138 * * *$ & $-0.0137 * * *$ & $-0.0136 * * *$ & -0.0122 & $-0.0114^{* * *}$ & $-0.0342 * * *$ & $-0.0295^{* * *}$ & $-0.0296 * * *$ & $-0.0346 * * *$ \\
\hline & [-4.6179] & {$[-4.5091]$} & {$[-4.3885]$} & {$[-0.9810]$} & {$[-3.0770]$} & {$[-6.2690]$} & {$[-7.3008]$} & {$[-7.2233]$} & {$[-6.1246]$} \\
\hline \multirow[t]{2}{*}{ Crédito Livre } & $0.0199 * * *$ & $0.0195^{* * *}$ & $0.0193^{* * *}$ & -0.0235 & $0.0146^{* * *}$ & $0.0165^{* *}$ & $0.0228^{* * *}$ & $0.0223 * * *$ & $0.0159 * *$ \\
\hline & [4.8907] & [4.7357] & [4.5811] & [-1.6285] & [2.8485] & [2.4296] & [4.2713] & [4.1214] & [2.2496] \\
\hline \multirow[t]{2}{*}{ Constant } & $-0.3726^{* * *}$ & $-0.3895^{* * *}$ & $-0.3989 * * *$ & $-0.1631 * * *$ & $-0.5065^{* * *}$ & $-0.2901 * * *$ & $-0.3266 * * *$ & $-0.3429 * * *$ & $-0.3140 * * *$ \\
\hline & {$[-15.0787]$} & {$[-15.0503]$} & {$[-14.7931]$} & {$[-6.2125]$} & {$[-11.7901]$} & {$[-11.3521]$} & {$[-13.2275]$} & {$[-13.2173]$} & {$[-11.1060]$} \\
\hline R-squared & 0.153 & 0.136 & 0.12 & 0.225 & 0.038 & 0.191 & 0.184 & 0.165 & 0.153 \\
\hline Liv=Dir & 0.0000 & 0.0000 & 0.0000 & 0.6063 & 0.0005 & 0.0000 & 0.0000 & 0.0000 & 0.0000 \\
\hline $\mathrm{N}$ & 4693 & 4485 & 4262 & 2289 & 2404 & 4219 & 4462 & 4254 & 3788 \\
\hline
\end{tabular}

${ }^{*} \mathrm{p}<.10,{ }^{* *} \mathrm{p}<.05,{ }^{* * *} \mathrm{p}<.01, \mathrm{t}$-statistic in brackets.

Tabela 12a - Regressões MQO por percentil: Pobreza x Crédito Total

\begin{tabular}{|c|c|c|c|c|c|c|c|c|c|}
\hline Dependent Variable & Pobreza2 & Cross Section & & & & & & & \\
\hline Percentile & $100 \%$ & $>5 \%$ & $>10 \%$ & $<50 \%$ & $>50 \%$ & $<90 \%$ & $<95 \%$ & 5 a $95 \%$ & 10 a $90 \%$ \\
\hline Regression & 4 & 4 & 4 & 4 & 4 & 4 & 4 & 4 & 4 \\
\hline \multirow[t]{2}{*}{ Crédito Total } & $-0.0091^{* * *}$ & $-0.0089 * * *$ & $-0.0088^{* * *}$ & $-0.0178^{* * *}$ & $-0.0068^{* * *}$ & $-0.0191 * * *$ & $-0.0139 * * *$ & $-0.0138^{* * *}$ & $-0.0188^{* * *}$ \\
\hline & {$[-8.0616]$} & {$[-7.8236]$} & [-7.5384] & {$[-3.6766]$} & {$[-5.0602]$} & [-9.0435] & {$[-8.3042]$} & {$[-8.1452]$} & {$[-8.5661]$} \\
\hline \multirow[t]{2}{*}{ PIB pc 2003} & 0.0003 & 0.0003 & 0.0004 & $-0.0211^{* * *}$ & $0.0014^{* * *}$ & $-0.0113^{* * *}$ & $-0.0075^{* * *}$ & $-0.0071^{* * *}$ & $-0.0103^{* * *}$ \\
\hline & {$[0.7382]$} & [0.9361] & [1.1093] & {$[-6.9372]$} & [3.4517] & {$[-9.5725]$} & {$[-8.0516]$} & {$[-7.4618]$} & {$[-8.3297]$} \\
\hline \multirow[t]{2}{*}{ Escolaridade } & $-0.0210^{* * *}$ & $-0.0196 * * *$ & $-0.0185^{* * *}$ & $-0.0338^{* * *}$ & 0.0057 & $-0.0186^{* * *}$ & $-0.0177^{* * *}$ & $-0.0169^{* * *}$ & $-0.0176^{* * *}$ \\
\hline & {$[-8.6869]$} & {$[-7.7644]$} & [-7.0506] & {$[-12.4760]$} & [1.4885] & {$[-7.3637]$} & {$[-7.1720]$} & {$[-6.5244]$} & {$[-6.3521]$} \\
\hline \multirow[t]{2}{*}{ Transferências União } & $-0.1802^{* * *}$ & $-0.1775^{* * *}$ & $-0.1762 * * *$ & $-0.1164 * * *$ & $-0.1597 * * *$ & $-0.1660 * * *$ & $-0.1761^{* * *}$ & $-0.1749 * * *$ & $-0.1658 * * *$ \\
\hline & {$[-20.5821]$} & {$[-19.8390]$} & {$[-19.1886]$} & {$[-9.9911]$} & {$[-12.8211]$} & {$[-18.2102]$} & {$[-19.7231]$} & {$[-19.1457]$} & {$[-17.2871]$} \\
\hline \multirow[t]{2}{*}{ Valor Bolsa } & $0.0365^{* * *}$ & $0.0377^{* * *}$ & $0.0391 * * *$ & $0.0087^{* * *}$ & $0.0569 * * *$ & $0.0259 * * *$ & $0.0298 * * *$ & $0.0311^{* * *}$ & $0.0287^{* * *}$ \\
\hline & {$[27.8088]$} & [27.6092] & [27.2849] & [6.1221] & [19.8403] & [18.4363] & {$[21.8533]$} & [21.8848] & [18.5989] \\
\hline \multirow[t]{2}{*}{ Constant } & $-0.3234^{* * *}$ & $-0.3351 * * *$ & $-0.3457^{* * *}$ & $-0.0799 * * *$ & $-0.5341^{* * *}$ & $-0.2368 * * *$ & $-0.2713^{* * *}$ & $-0.2820^{* * *}$ & $-0.2555^{* * *}$ \\
\hline & {$[-21.6036]$} & {$[-21.4129]$} & {$[-21.2478]$} & {$[-4.8516]$} & {$[-21.6862]$} & {$[-15.3161]$} & {$[-17.9534]$} & {$[-17.7769]$} & {$[-14.9597]$} \\
\hline R-squared & 0.513 & 0.495 & 0.473 & 0.391 & 0.238 & 0.543 & 0.539 & 0.521 & 0.505 \\
\hline $\mathrm{N}$ & 4693 & 4485 & 4262 & 2289 & 2404 & 4219 & 4462 & 4254 & 3788 \\
\hline
\end{tabular}


Tabela 12b - Regressões MQO por percentil: Pobreza x Crédito Origem

\begin{tabular}{|c|c|c|c|c|c|c|c|c|c|}
\hline Dependent Variable & Pobreza2 & Cross Section & & & & & & & \\
\hline Percentile & $100 \%$ & $>5 \%$ & $>10 \%$ & $<50 \%$ & $>50 \%$ & $<90 \%$ & $<95 \%$ & 5 a $95 \%$ & 10 a $90 \%$ \\
\hline Regression & 8 & 8 & 8 & 8 & 8 & 8 & 8 & 8 & 8 \\
\hline \multirow[t]{2}{*}{ PIB pc 2003} & 0.0002 & 0.0003 & 0.0003 & $-0.0210 * * *$ & $0.0014^{* * *}$ & $-0.0105^{* * *}$ & $-0.0073 * * *$ & $-0.0068 * * *$ & $-0.0095^{* * *}$ \\
\hline & [0.5895] & [0.7921] & [0.9701] & {$[-6.8963]$} & [3.3011] & {$[-8.8598]$} & {$[-7.7914]$} & {$[-7.2012]$} & {$[-7.6324]$} \\
\hline \multirow[t]{2}{*}{ Escolaridade } & $-0.0236 * * *$ & $-0.0224 * * *$ & $-0.0214^{* * *}$ & $-0.0343 * * *$ & 0.0023 & $-0.0222^{* * *}$ & $-0.0210 * * *$ & $-0.0204 * * *$ & $-0.0216^{* * *}$ \\
\hline & {$[-9.6595]$} & {$[-8.7491]$} & {$[-8.0372]$} & {$[-12.5151]$} & [0.5913] & {$[-8.6557]$} & {$[-8.3907]$} & {$[-7.7604]$} & {$[-7.6658]$} \\
\hline \multirow[t]{2}{*}{ Transferências União } & $-0.1735^{* * *}$ & $-0.1711^{* * *}$ & $-0.1698 * * *$ & $-0.1153^{* * *}$ & $-0.1547 * * *$ & $-0.1590 * * *$ & $-0.1688 * * *$ & $-0.1677^{* * *}$ & $-0.1589 * * *$ \\
\hline & [-19.7552] & {$[-19.0620]$} & {$[-18.4462]$} & {$[-9.8636]$} & {$[-12.4178]$} & {$[-17.4223]$} & {$[-18.8634]$} & [-18.3324] & {$[-16.5579]$} \\
\hline \multirow[t]{2}{*}{ Valor Bolsa } & $0.0358^{* * *}$ & $0.0369 * * *$ & $0.0384^{* * *}$ & $0.0087^{* * *}$ & $0.0569 * * *$ & $0.0254 * * *$ & $0.0292 * * *$ & $0.0304^{* * *}$ & $0.0281 * * *$ \\
\hline & [27.2887] & [27.0851] & [26.7841] & [6.0788] & [19.9152] & [18.1672] & [21.4712] & [21.4916] & [18.3168] \\
\hline \multirow[t]{2}{*}{ Crédito Direcionado } & $-0.0180^{* * *}$ & $-0.0179 * * *$ & $-0.0177^{* * *}$ & $-0.0253^{* * *}$ & $-0.0140 * * *$ & $-0.0362 * * *$ & $-0.0264 * * *$ & $-0.0264 * * *$ & $-0.0361 * * *$ \\
\hline & {$[-9.9228]$} & {$[-9.7014]$} & {$[-9.4395]$} & {$[-3.2373]$} & {$[-6.5690]$} & {$[-10.9766]$} & {$[-10.6633]$} & {$[-10.5071]$} & {$[-10.5753]$} \\
\hline \multirow[t]{2}{*}{ Crédito Livre } & $0.0046^{*}$ & $0.0048^{*}$ & $0.0049 *$ & -0.0086 & 0.0047 & 0.0047 & 0.0053 & $0.0055^{*}$ & 0.0055 \\
\hline & [1.8791] & [1.9054] & [1.9395] & {$[-0.9491]$} & [1.5997] & [1.1432] & [1.6362] & [1.6626] & [1.2803] \\
\hline \multirow[t]{2}{*}{ Constant } & $-0.3133^{* * *}$ & $-0.3242^{* * *}$ & $-0.3343^{* * *}$ & $-0.0790 * * *$ & $-0.5201 * * *$ & $-0.2275^{* * *}$ & $-0.2608 * * *$ & $-0.2705^{* * *}$ & $-0.2444 * * *$ \\
\hline & [-20.8895] & {$[-20.6672]$} & {$[-20.4913]$} & {$[-4.7873]$} & {$[-21.0199]$} & {$[-14.7292]$} & [-17.2615] & [-17.0475] & {$[-14.3218]$} \\
\hline R-squared & 0.517 & 0.499 & 0.477 & 0.391 & 0.243 & 0.547 & 0.544 & 0.526 & 0.510 \\
\hline Liv=Dir & 0.0000 & 0.0000 & 0.0000 & 0.2254 & 0.0000 & 0.0000 & 0.0000 & 0.0000 & 0.0000 \\
\hline $\mathrm{N}$ & 4693 & 4485 & 4262 & 2289 & 2404 & 4219 & 4462 & 4254 & 3788 \\
\hline
\end{tabular}

O mesmo padrão de sensibilidade dos resultados apresentados anteriormente se repete nos resultados relativos à pobreza. Ou seja, é muito pequena a sensibilidade das estimações em relação aos percentis mais reduzidos. Além disso, quando há exclusão dos indivíduos dos percentis mais elevados da amostra, há aumento em valor absoluto do coeficiente da variável crédito direcionado para ambas variáveis dependentes e a estimativa para o crédito livre deixa de ser estatisticamente significativa para a variável dependente pobreza (Tabela 12b).

Simultaneamente, e reflexo dos resultados anteriores, a estimativa do crédito total assume valor ainda mais negativo para ambas medidas de pobreza e passa a ser estatisticamente significativa no caso da regressão cuja variável dependente é a pobreza extrema. 


\section{CONCLUSÃO}

Em primeiro lugar, os resultados apresentados, com dados locais, em nível municipal, fornecem evidências adicionais aos resultados já consagrados pela literatura internacional e nacional (com dados de estados): há uma correlação positiva entre desenvolvimento financeiro e desenvolvimento econômico.

Além disso, os resultados apresentados sugerem que o crédito livre, em geral, apresenta uma maior eficiência em favorecer o crescimento do que o crédito direcionado. Por outro lado, o crédito direcionado parece ser utilizado como um instrumento adicional de política pública ao apresentar resultados muito positivos em termos de colaborar na redução da desigualdade e da pobreza. Vale fazer a ressalva de não ser possível saber quais resultados poderiam ser obtidos se os recursos alocados para subsídios de empréstimos, que constituem grande parte do crédito direcionado, fossem alocados para políticas públicas com a mesma finalidade e nem de uma estimativa precisa do gasto total e sua falta de transparência no orçamento público brasileiro.

Esses resultados são ainda mais fortes quando são desconsiderados os municípios com renda per capita mais elevada. Isso sugere uma dinâmica diferente desse grupo em relação à média e em relação àqueles de renda per capita mais baixa.

Por fim, esses resultados poderão ser aprofundados, no futuro, com uma maior disponibilidade de dados na dimensão temporal. 


\section{REFERÊNCIAS BIBLIOGRÁFICAS}

BANCO CENTRAL DO BRASIL. O que é o SCR. Banco Central do Brasil, Julho 2013. Disponível em: <http://www.bcb.gov.br/?SCROQUE>. Acesso em: 15 jul. 2013.

BARRO, R. J; Economic Growth in a Cross Section of Countries. Quarterly Journal of Economics, v. 106, p. 407-443, 1991.

BARRO, R. J.; SALA-I-MARTIN, X. Convergence across States and Regions. Brooking Papers Econ. Activity, No. 1, p. 107-182, 1991.

BARRO, R. J.; SALA-I-MARTIN, X. Convergence. The Journal of Political Economy, v. 100, n. 2, p. 223-251, 1992.

BENCIVENGA,V. R.; SMITH, B. D. Financial Intermediation and Endogenous Growth. Review of Economic Studies, v. 58, p. 195-209, 1991.

BURGUESS, R.; PANDE, R. Do Rural Banks Matter? Evidence from the Indian Social Banking Experiment. The American Economic Review, v. 95, n. 3, p. 780-795, 2005.

GOLDSMITH, R. W. Financial Structure and Development. New Haven, 1969.

GREENWOOD, J.; JOVANOVIC, B. Financial Development, Growth, and the Distribution of Income. The Journal of Political Economy, v. 98, n. 5, p. 1076-1170, 1990.

GUISO, L.; SAPIENZA, P.; ZINGALES, L. Does Local Financial Matter? The Quarterly Journal of Economics, v. 119, n. 3, p. 929-969, August 2004.

HSIEH, C. T.; KLENOW, P. J.; Misallocation and Manufacturing TFP in China and India. The Quarterly Journal of Economics, v. 124, n. 4, p. 1403-1448, 2009. 
JAYARATNE, J.; STRAHAN, P. E.; The Finance-Growth Nexus: Evidence from Bank Branch Deregulation. The Quarterly Journal of Economics, v. 111, n. 3, p. 639-670, 1996.

KING, R. G.; LEVINE, R.; Finance and Growth: Schumpeter Might Be Right. The Quarterly Journal of Economics, v. 108, n. 3, p. 717-737, August 1993.

LA PORTA, R.; LOPEZ-DE-SILANES, F.; SHLEIFER, A.; VISHNY, R.W. Law and Finance. Journal of Political Economy, v. 106, n. 6, p. 1113-1155, December 1998.

LEVINE, R. Financial Intermediary Services and Growth. Journal of the Japanese and International Economies, v. 6, n. 4, p. 383-405, December 1992.

LEVINE, R.; LOAYZA, N.; BECK T. Financial Intermediation and Growth: causality and causes. Journal of Monetary Economics, v. 46, n. 1, p. 31-77, August 2000.

MCKINNON, R. Money and Capital in Economic Development. Washington DC, 1973

NARITOMI, J.; SOARES, R. R.; ASSUNÇÃO, J. J. Rent Seeking and The Unveiling of 'De Facto' Institutions: Development and Colonial Heritage within Brazil. NBER Working Paper Series, No 13545, National Bureau of Economic Research, October 2007.

RESTUCCIA, D.; ROGERSON, R. Policy Distortions and Aggregate Productivity with heterogeneous Plants. Review of Economic Dynamics, v. 11, n. 4, p. 707-720, 2008.

SHAW, E. Financial Deepening in Economic Development. New York, 1973.

YEYATI, E. L.; MICCO, A.; PANIZZA, U. Should the Government Be In The Banking Business? The Role Of State-Owned and Development Banks. Washington, DC: Research Department Working Papers, No 517, Inter-American Development Bank, 2004 
ZARA, T. M. Desenvolvimento Financeiro, Crescimento e Desigualdade nos Estados

Brasileiros. São Paulo: [s.n.], 2006. Dissertação (Mestrado em Teoria Econômica) Faculdade de Economia, Administração e Contabilidade, Universidade de São Paulo. 